\title{
Ein ägyptischer Dialog über die Schreibkunst und das arkane Wissen
}

\author{
Joachim Friedrich QuACK
}

Die vor kurzem erschienene Publikation des Werkes, das von seinen Bearbeitern als "Thotbuch" bezeichnet wird, ${ }^{1}$ hat große Aufmerksamkeit verdient. Inhalt des Textes ist vorrangig ein Dialog zwischen einem "Weisheitsliebenden“ ( $m r \underline{i}-r h$ ), den ich im folgenden auch als den "Kandidaten" bezeichnen will (wer etwas dreister ist, kann ihn in wörtlicher Bedeutung des griechischen Kompositums als "Philosoph" wiedergeben) und seinem Mentor und Examinator, der als $h r=f n$ hsr.t ("so sagte er in Heseret") oder $h r=f n h s-r h$ bezeichnet wird und nach Meinung der Herausgeber eine Form des Thot darstellt. Ich wäre hier eher skeptisch, da Thot im Text als klärlich von dem Dialogpartner unterschiedene Gestalt erwähnt wird. In einigen Passagen vor allem des hinteren Teils (z. B. B02, 11/11 ff.) spielt auch eine Gestalt namens $w p i-t p-3 . t=f$ eine größere Rolle. Ich würde vorschlagen, den hinteren Bestandteil als Schreibung für $t p-i 3 . t=f$, auf seiner Standarte" aufzufassen, wobei der vordere Bestandteil "der Öfner" eventuell eine Kurzform für $W p \underline{i}$-w3i. $w$. , den "Wegöffner“, darstellt, also eine typischerweise auf Standarten dargestellte Geleitgottheit in Schakalsgestalt. Weiterhin greift auch der Türhüter des Lebenshauses ins Gespräch ein (C02.1, 4). Eine Gestalt $g l g=f n$; b. w „er hat die Seelen (d.h. Bücher) gefangen“" (V01, 2/18 u. Par.; B01, 2/4; eventuell auch V01, 4/14 f.) mischt sich ebenfalls ein. Auch ein $k m 3=f n 3 m^{3} w y$,er hat die Gedanken geschaffen“ ist B02, 11/2 als Redner belegt.

Der Text ist in (relativ langen) Versen strukturiert und in der Mehrzahl der Zeugen auch durch stichische Schreibung äußerlich klar strukturiert; von den nicht stichisch geschriebenen weisen einige (V01 und B01) teilweise eine Markierung der Versgrenzen durch kleine Spatien auf. Die Handschrift B02 zeigt öfters innerhalb eines Verses noch Punkte unter der Zeile, deren Funktion allerdings nicht recht klar wird. Aller Wahrscheinlichkeit nach ist der Anfang des Werkes, und damit auch der Titel, weitgehend erhalten. Im Folgenden soll eine durchgehende deutsche Übersetzung zumindest der leidlich gut erhaltenen

1 Richard Jasnow, Karl-Theodor Zauzich, The Ancient Egyptian Book of Thot. A Demotic Discourse on Knowledge and Pendant to the Classical Hermetica (Wiesbaden 2005). Vgl. dazu J.F. Quack, Die Initiation zum Schreiberberuf im Alten Ägypten, SAK 36 (2007), 249-295; in letzterem Beitrag finden sich auch Begründungen für meine gegenüber der Erstbearbeitung nicht selten abweichenden Lesungen und Übersetzungen. 
Passagen geboten werden. Um eine Orientierung im Text, und damit auch den Abgleich mit der (nicht selten anders verstehenden) Edition zu erleichtern, sind hier die Zeilenzählungen nach den wichtigsten Handschriften in 10-ZeilenAbständen angegeben. ${ }^{2}$ Ich setze dabei, einer Vermutung der Herausgeber folgend, ${ }^{3}$ ein größeres Segment nicht völlig sicherer Plazierung an den Anfang des Textes, da seine ersten Zeilen ganz wie eine Überschrift des Gesamtwerkes klingen.

$(B 07,1)$ „[Die Worte], welche den Knaben erziehen und den Sohn eines Wen-Ima ${ }^{4}$ beraten lassen $[. .$.

[...] Schutz, Priester des Osiris Neferhotep, des großen Gottes, ...

[...] seinen Leib darbringen dem Neb-Hetep, ... der Seschat in [all ihren] Namen,

[...] der „Löserin der beiden Hörner", ${ }^{5}$ Vorschrift zum Eintreten in die Kammer der Finsternis.

[...] indem sie reif(?) sind, indem sie groß(?) an Ruhm(?) mit deinen Aussprüchen sind.

[...] vier Gesichter, während ihre Fundamente keine Fäulnis kennen.

[...] indem sie Hirten sind zum Hüten der Schrift der Gottesworte.

[...] indem sie gar sehr wirksam(?) sind, wenn du sie nicht zur Last machst.

$[, . .$.$] Gold(?) Nebhetep, wenn du wünschst, sie zu hören, dann setze sie an$ deine Ohren(?), um sie zu hören! ${ }^{6}$

$(B 07,10)[\ldots]$ heute beim Überlegen von Wahrheiten, mögest du ihren Geschmack schmecken!

[...] ich es zu [zu deinem Charakter] als Vorschrift

[indem sie emsiger sind] als eine Biene(?), indem sie [...] sind als Tiere, indem sie kundig sind der nützlichen Aussprüche.

[...], Jedermann trinkt nach seinem Rang.

[Der Abkömmling von] Kundigen, zugehörig zu Isdes, ein Sohn eines WenIma, dem Nebwenenef gehörend, er sagte:

2 Dabei ist die erste Kolumne des angeblichen Fragments B05, das tatsächlich zur selben Handschrift wie B04 gehört, als B04, Kol. 0 gezählt, in der Hoffnung, daß dies vergleichsweise am wenigsten Verwirrung auslöst.

3 Jasnow, Zauzich, Book of Thot, S. 375.

4 Hierzu s. den Kommentar in der Edition, S. 31; bei Korrektur der Úbersetzung der Hungersnotstele sollte sich klar ergeben, daß wn-lm(3) ein Epitheton oder Titel des Imhotep ist; vgl. D. Wildung, Imhotep und Amenhotep. Gottwerdung im alten Ägypten, MÄS 36 (München/Berlin 1977), S. 150; R. B. Gozzoli, The Writing of History in Ancient Egypt during the First Millennium BC /ca. 1070-180 BC). Trends and Perspectives, GHP Egyptology 5 (London 2006), S. 256.

5 Ein typisches Epitheton der Schreibgöttin Seschat.

6 Vgl. die ähnliche Formulierung Amenemope 3, 9. 
[„...] Ich erwachte in der Kammer der Finsternis, die Eierschale (?) des Ibis auf seiner Gestalt.

[Ich bin es,] der hört in der Kammer der Finsternis, in den Geheimnissen der Geister,

[der] wünscht zu bellen unter den Hunden der Seschat, der Großen.

Mein eigenes Herz ist es, das mich herbeigebracht hat; möge ich eins werden mit den Knaben! ${ }^{47}$

(L02, 1/1) [...] sagte: „Wer bist du, welcher ist es, der für dich gesucht hat, wer ist es, der deine Stricke erzeugt hat?"

(B07, 20) [Er antwortete]: „Ich, der Weisheitsliebende, bin es, den er gesucht hat; die Sprachkunst des Ibis ist es, die mich gebunden hat, um [mich] abzutasten."

[Er-sprach-in-Hesrech sagte]: „Klopf nicht an die Höhlen(tür), wenn du ihre Gestalt nicht kennst, komm der Hand der [...] nicht nahe!

[... ] die [...] sind Dolerit, die Kehle ist Eisen!"

[Der Weisheitsliebende sagte:] „Diejenige, welche meine Kehle als Kehle aus Erz ge[gossen hat], laß mich mit euch bellen!

[...] während die fähigen Geister in meinem Herzen sinnen, ich habe meinen Rücken den Babys(?) zugewandt.

[Er-sprach-in-Hesrech] sagte: „Wenn du wie Myrrhe duftest, dann tritt nicht in das Lebenshaus! Geile Stiere sind es, die in [ihm] sind.

Gibt es für dich eine Frau? Hast du Töchter? Dann gib acht!

[...] dich; oder ist es ein Vater, der dich ausgeschickt hat? Die Lehre des Knaben(?) ist es, die es wert ist, dich zu mustern."

(L02, 1/10) Der Weisheitsliebende sagte: „Ich kenne die Tabus, die in der Kammer der Finsternis herrschen, ich bin gekommen frei von ihnen.

Ich habe mir den Wein zum Abscheu gemacht, ich habe den Duft von Myrrhe vergessen. Siehe, meine Kleider sind zerlumpt, ich bin begierig!“.

(B06, 1/1) Er-sprach-in-Hesrech sagte: „Die Ibisse, die hier sind, ihre Nahrung ist mühselig, ihr Leben ist problematisch.

Sie sättigen sich nicht an Brot, sie betrinken sich nicht mit Wein, sie salben sich nicht mit Salböl. Ihr Tabu ist, den Namen des Beilagers zu nennen.

Pfeildämonen(?) sind es, die an ihrem Mund bleiben, und Schlangen auf ihren Lippen.

Ihre Opfergaben sind Hunde, ihre Nahrung Esel, ihre Früchte die Reptilien.

Wirst du leben können mit denen, die in ihren Erdlöchern sind? Was ist ihre Art, ihnen zu dienen?"

Der Weisheitsliebende sagte: „Ich werde ihre Schreibnäpfe waschen, ich werde die Schreibtafeln abspülen(?), ich werde den Staub der Kästen entfernen.

7 Eine Handschrift fügt hinzu „den Toten“. 
(L02, 2/1) Ich werde die Reste auffüllen, ich werde die Fackel anzünden, ich werde Holzkohle bereitstellen für die Tempelhäuser.

Ich werde die Steine brechen(?), ich werde die Kästen umarmen, ich werde [...] erzeugen.

(B06, 1/10) Ich werde die Kästen(?) empfangen, ich werde auf die Stimme herbeieilen, ich werde [die Türen(?)] öffnen.

Ich werde die Schriftrollen auf dem Weg hinter ihnen tragen, ich werde $[\ldots]^{\text {ct }}$

Er-sprach-in-Hesrech sagte: „Hast du einen Traum? Sieh sie, die Kammer der Fin[sternis! Ich werde dein] Schiffer [sein].“

Der Weisheitsliebende, er sagte: „Begib dich hinter mich! Der Schlaf ist abgeworfen(?). Ich komme zu [...] des Traums."

Er-sprach-in-Hesrech sagte: „Der Stier, welcher der ... folgt, ... seine Farbe $[\ldots]$.

Er-sprach-in-Hesrech sagte: „Gehilfe des Meisters Neb-Hetep! sein!

[...] in deinen eigenen Gliedern, sagend: ,Ich werde ein Pavian unter ihnen

(L02, 2/10) [Ich werde] dich nach vorne [bringen in den] Buchsammlungen, ich will dich stehen lassen [...] Schlange, die in [...]

[...] was auf [...], indem er einen Falken herbeibringt

[...] leben [die] Handwerker des Lebenshauses, die Chnume (B06, 1/20) [...]

[...] Ammen der Götteridole.

[...] ... wegen des Sagens der Anzeige.

(B06, 2/1) Was ihr Fleisch empfangen hat, das wird ihnen ihr Denken geben, man wird [sie] verurteilen wegen des Verschmachtens(?).

Anspannend sind sie, die Schriften wegen des Findens ihrer Süße, ${ }^{8}$ sie werden einen Lande[pflock für] die Herzen bilden.

Möge man meine Stimme hören, möge ich ... in einer Stunde des Lauschens der Meldung wegen einer Frau.

Ich werde im Hinblick auf mich zählen wegen des Nachdenkens über die Art der Lebenszeit, ich [werde ...]

[...] ... [...] ihre Hand im Kasten der Bücher, [indem] sie kennen den [...]

[...] sitzen, während eine Erziehung(?) vor ihnen ist.

(F01.2, 1) wobei sie kundig sind der sieben [... Proto]kolle(?) der Könige der jeweiligen Zeit,

und die [...] veranlassen, daß sie die Namen in diesem Lande sagen,

8 Oder ,Umarmung“.

9 Vgl. hierzu Amenemope 3, 14 (Türschwelle für das Herz) und 3, 16 (Landepflock für die Zunge). 
und ich belebe die Abbilder der Götter, [die ..].. der beiden großen Neunheiten. Götter.

[...] der veranlaßt, daß man sie zählt(?) in ... ... die Kapitel/Tafeln der

$(\mathrm{C} 07.5,10)$ Während ihre (B06, 2/10) Hunde und ihre Paviane dastehen, indem sie sprechen mit ihrer Stimme in einer kurzen Stunde,

[... Gehilf]e(?) des Weisen, bestimmt(?) für das Herrscheramt des Königs von Unterägypten,

wobei $[\ldots]$ nach vielen Jahren, wenn sie vergangen sind.

Ich fand [...] Millionen und eine Tochter.

Ich erkannte die $\mathrm{Kraft}(?)$ [...]. zum [...]

Die Kinder des Frevlers(?) sind es, die dauern [...]

[...] kommen zu euch(?), um einzutreten in die [...], möge sie [...]

[...]..., der Charakter, die [...] Geister [...]

$[\ldots]$... sein Herz, ich $[\ldots]$

$[\ldots]$ ich werde $[\ldots] \ldots$

[...] er(?) sagte ... Augen, hören [...]

[...] ... es zum Dromos der Geister [...]

[...] er enthüllte es zu dem Feld des Gewürms [...] Augen [...]

Hiernach ist der Text zunächst einmal für einen nicht genau abschätzbaren Bereich verloren (bzw, allenfalls unplazierbare Kleinfragmente erhalten).

Vom Textinhalt her eventuell hierherzustellen ist ein kleines Fragment mit Zeilenanfängen (B12):

[...]

Arbeite mit deiner Hand, sprich [...]!

... die Finsternis nicht, um ... [...]!

Geh vorbei am Haus [...], liebe es, in es einzutreten [...]!

Kommandiere deine Beine dazu, nicht hin- und herzugehen [...]!

Leid für die Kraft von Herz und Zunge [...]

Der Weisheitsliebende sagte: "Meine Speise, meine A[rt ...].“

Er sprach in Heseret sagte: „Hunger [...]

Mit gewisser Wahrscheinlichkeit ist auch ein anderes Fragment etwa in diesem Bereich der Komposition unterzubringen (B08 mit Parallele in B06.3):

$(\mathrm{B} 08,1)$ Die $[\ldots]$

Oh du mit auserlesenem Denken, indem er ü[berlegt(?) ...] Weg der [...].

... Oberteil [...] ihre Vorratshäuser.

Du wirst erleuchten im Speicher, und das Auge [...] Lampe.

Du wirst aufsteigen auf das Dach des Pronaos, du wirst [...]

Du wirst [...], ohne daß sie einen Rest haben, die Gedanken [...]"

Der Weisheitsliebende sagte. „Möge man mich in ihre [...] ... [...]!“ 
Er sprach in Heseret sagte: „Diese Ämter(?), die ich dekretiert habe [...] Oh du, der gekommen ist, um eine Stellung einzunehmen [...]! (B08, 10) Komm, dann enthülle ich sie nach [ihrer] Art [...]!

Versuchsweise ebenfalls in diesem Lückenbereich untergebracht sei ein weiteres Bruchstück (C02.1 mit Parallele in Y01.1 und Y01.2). ${ }^{10}$

$(\mathrm{C} 02.1, \mathrm{x}+1)[\ldots]$. dich ... [...] dann wirst du [...]

[...] Türhüter meiner [...], der Wächter der Lehren des Lebens. ${ }^{11}$

$[\ldots]$... [...] ich öffnete sie, die Kästen Wolf [...] ${ }^{\star}$

[Der ...] der Dokumente, der Türhüter des Lebenshauses, er sagte:

„[Komm(?)] zum Haus des Lebensfangens(?), oh Wolf, der Kunde gesprochen hat(?) in der Kammer der Finsternis.

[...]... der deine Kehle(?) verschlossen hat, damit du zum Gehilfen des Stieres und des Hundes wirst.

[...] sehen seinen Kanal von Fett, indem er enthüllt ist vor dir, wie er überströmt.

[Trin]k mit deiner Zunge, iß mit deinem Mund, möge die Lehre wachsen in deinem Leib!

[...] ist, was in seinem Brunnen ist, indem er es ergießt, wie er will(?).

[...] ist, was in seiner Höhle ist, der Wissende der beiden Länder, der in seinem Herzen erwägt.

Millionen und Abermillionen nennt man ihn; daß man davon ißt, bedeutet, daß er geboren wird.

Seschat(?) die Große ist es, die ihn umarmt, Satis/Sothis ist es, die ihn zu seiner Zeit ausgießt.

Wohl auf das Wirken des Thot geht eine Passage, die in vier Textzeugen leidlich erhalten ist: ${ }^{12}$

[..., wobei] er Atum(?) nicht hat, die Gebärmutter(?) des [...] Magie(?)

[Als er ...] als Name des Guten nannte, da sagte er es im Hinblick auf die Speicher des Lebens. ist.

$(\mathrm{C} 04.7,2 ; \mathrm{B} 14.1,1 / 1)[\ldots]$ die angekommen(?) ist, ohne daß ... unter ihr

(Y01.3+4, 1) Kämpf für ihn voran! [Wer] kämpft, zu dem wird er kommen.

10 Die schlechte Lesbarkeit der Photographie ermöglicht es nicht, die Stücke in Yale vollständig heranzuziehen.

11 Für diesen Ausdruck vgl. Amenemope 1,1.

12 Hier sind auch zusätzliche Fragmente von pCarlsberg 616 relevant, deren Kenntnis ich Kim Ryholt verdanke. 
Das Recht auf dem Haus dessen, der auf dem Thron sitzt, [er wird] es lieben, er wird es bezaubern.

Als er Leben schuf unter dem Kopf des Menschen, da machte er es im Hinblick auf Wasser und die Reste(?).

Als er "Gefilde“ als Namen des Feldes nannte, da sagte er es im Hinblick auf die Kühe, die pflügen. ${ }^{13}$

Als er "Stier“ als Name der Überschwemmung nannte, da sagte er es im Hinblick auf die Stiere, die sich anstrengen.

Als er „Rest “(?) als Name der Kräftigen(?) nannte, da sagte er es im Hinblick auf die Dreschtenne mit Frucht. ${ }^{14}$

$(C 04.7,10)$ Die Gerste, welche ... erschaffen hat für das Feld, ihr Name ist ... von Gold.

$(Y 01.3+4,10)$ Lapislazuli und Malachit - die vortrefflichen Länder werden sie hervorbringen als Schilf(?). ${ }^{\text {c15 }}$

Er sprach in Heseret sagte: „Hast du gesehen, hast du gejubelt(?) bei seinem Aufgang?"

Der Weisheitsliebende sagte: „Sein [...] - möge ich es kennen, so daß ich niedersinke(?) und sein Abbild ..."

Er sprach in Heseret [sagte]: „[...] im Raum der Finsternis, die Seelen des $\operatorname{Re}($ ?) darin.

$[\ldots \ldots \ldots] \ldots . . . .$.

Der Weisheitsliebende sagte: [...] Wohnstätte; möge dein Name erscheinen als Abbild [...]

[........ von Millionen, indem er [Wasser] durch die Kanäle zieht.

$[\ldots \ldots \ldots]$, indem er Schreiber der Lehren ist.

$[\ldots \ldots \ldots]$ seine $[\ldots]$.

$[\ldots \ldots . . .$.$] seinen Neunheit [\ldots]$.

Wo schließlich wieder ein verständlicher und kontinuierlicher Zusammenhang einsetzt, erhält der Kandidat Ermahnungen für sein Verhalten, insbesondere aber eine Ermunterung zum Lernen. Dabei changiert der Text auch zwischen dem konkreten Fangen von Vögeln und Fischen und einem abstrakten Erjagen des Wissens, was zweifellos dadurch befördert wird, daß in einer religiösen Tradition Thot wesentlich beim Vogelfang beteiligt ist. ${ }^{16}$

13 Wohl ein Wortspiel zwischen ih.t ${ }_{n}$ Feld" und ih.t "Hathorkuh" (LGG I, 48 f.).

14 Hier dürfte ein Spiel mit dem Wort $s p$ vorliegen, daß eigentlich "Rest" bedeutet, aber mit dem Zeichen der Tenne geschrieben wird.

15 Eventuell handelt es sich um eine Kontrastierung von mineralischem und vegetabilem Grün, wie sie in der bekannten Passage im Mythos vom Sonnenauge pLeiden I 384, 6, 3-30 vorliegt.

16 Vgl. Quack, SAK 23 (1996), S. 323. 
(V01, 2/1; F12, 1) „Nimm deinen Kasten der Seschat nicht in das Haus deines Arztes, wenn dein [...] ...

Berühre nicht eine Schutzhülle(?) auf deinem Wasserkrug an deinem Tag des $[\ldots]$...

Es gibt zwei Gestalten als Werk der Palette, welche oben auf seinen [...] sind.

Wirst du vorbeistreichen(?), um die Palette erscheinen zu lassen an den Riemen .[...]?

Wirst du die Nacht wachend verbringen in dem Kasten der Holzkohle, wirst du [...] finden [in der Kammer] der Finsternis?

Hüte dich, hüte dich unter ihnen! Sei nicht matt für sie, sei stark im Herzen!

Kämpf, dann lernst du die Formel der Gottesanbetung für ihn, flehe an $[\ldots]$ !

Verabscheue sein Tabu, liebe, was er liebt, vereine sein Wesen an deiner Haut!

Wer ist es, der dich großziehen wird, und dich [...] wird in den Pforten deiner Erziehung(?)?

$(\mathrm{F} 12,10)$ Beherzige(?) die Aufzucht durch deinen Vater, sie ist bedeutsam!

Er belehrt zu ... der Milch (V01, 2/10) deiner Amme, der Mutter [...]

Saug an seinem Mund, seine Zunge ist eine Brust, sein Rücken(?) ist eine Säule(?)!

... seine ... nicht; sie sind alle Atem [des Lebens(?)]!

Ermatte nicht, an seinen Aussprüchen zu saugen; sie sind goldene Ähren!“

Er hat die (Buch)seelen erjagt, er hat die Hunde der Oase [...] des Herrn von Hermopolis gefangen,

Er öffnete seinen Mund, er antwortete seinen Gehilfen des Meisters(?) NebHetep:

${ }_{n}$ Die Seelen des Re, sie sind Herren der Zahl(?), sie umarmen(?) den Wissenden. legen.

Er ist ihr Hirte, der ihnen Nahrung verschafft, um sie in seine Hand zu Staub."

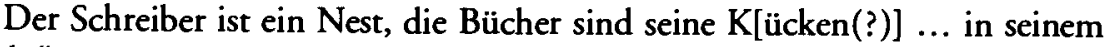

Der Weisheitsliebende sagte: "Ich wünsche, ein Fischer nach den Anbetungen des Isden zu sein, und daß ich seine "Seelen" fange."

Er-hat-die-Seelen-gefangen sagte: „Dein Fangnetz hat gefangen, was auf der Zunge deines Mundes ist, dein ..., was auf deiner Brust(?) ist.

$(F 12,20)$ Deine Netze haben gefangen, was [auf] (V01, 2/20) seiner Nase ist; deine Angelhaken, was auf seinem .[..] ist.

Die Fische und Vögel, die in sein [..] hineingehen, ich habe für ihn ... geschützt, [sie werden den] Mund [nicht] öffnen. 
Bedränge sie, ermatte nicht, sie zu fangen! Man ißt nicht von [...] des Speichers.

Man fürchtet sich nicht vor der Vergeltung eines Jahrs des Elends, man stirbt nicht an einem Jahr der [Not(?)].

Wenn du [...] fängst, übergeht man dich nicht; es sind [ke]ine Schwierigkeiten.

Ein Fischfang in ihre Hände ist, worin sie sind, [indem] sie in ihrem Netz gefangen sind.

Wenn du auf dem Weg hin- und hergehst, indem sie hinter dir sind, verlä[ß̊t(?)] man [dich(?)] nicht.

Alle Hirten beschaffen Nahrung für ihr Anvertrautes; diese sind es, die ihr [...] machen."

Der Weisheitsliebende sagte: „Das Netz [... möge] ich eins mit seinen Jägern sein.

Möge man mich vor die Falle setzen [...].“ (V01, 2/1-3/24 sowie C09, 1/ 24-2/27 mit Parallelen).

Die Jagdmetaphorik scheint sich in einer schlecht erhaltenen Passage noch weiter fortzusetzen. Sie eröffnet übrigens ganz neue und bislang nie erahnte Optionen, wie man die Darstellungen von Vogel- und Fischfang in den ägyptischen Gräbern verstehen kann ${ }^{17}$ bzw. die Ägypter in der Spätzeit sie ausgedeutet haben könnten. Eventuell sind auch Kompositionen wie "The Pleasures of Fishing and Fowling" und "The Sporting King ${ }^{\text {"18 }}$ unter diesem Gesichtspunkt neu zu bewerten. Wo der Dialog wieder zusammenhängender einsetzt, enthält er eine Passage über die verschiedenen Einflüsse auf die Charakterbildung, der selbst in der heutigen pädagogischen Diskussion noch von Interesse sein dürfte:

(B01, 1/1) „Er-sprach-in-Hesrech sagte: „Leitest du den an, der zu handeln versteht, oder ist es eine Belehrung des Weisen, die man vornimmt?

17 Zum Problem vgl. u. a. E. Feucht, Fisch- und Vogelfang im wiç-wr des Jenseits, in. I. Shirun-Grumach (Ed.), Jerusalem Studies in Egyptology, ÄAT 40 (Wiesbaden 1998), S. 37-44; J. Assmann, Altägyptische Totenliturgien, Band 1. Totenliturgien in den Sargtextsprüchen des Mittleren Reiches (Heidelberg 2002), S. 46-50; R. van Walsem, Iconography of Old Kingdom Elite Tombs. Analysis \& Interpretation, Theoretical and Methodical Aspects (Leiden/Leuven/Dudley 2005), S. 72-80; H. Altenmüller, „Wasservögel sollen zu dir kommen zu Tausenden." Aspekte der Fisch- und Vogeljagd im Papyrusdickicht, Nikephoros 18 (2005), S. 39-52.

$18 \mathrm{Zu}$ ihnen s. zuletzt R.B. Parkinson, Poetry and Culture in Middle Kingdom Egypt. A Dark Side to Perfection (London/New York 2002), S. 226-232; G. Burkard, H.J. Thissen, Einführung in die altägyptische Literaturgeschichte I. Altes und Mittleres Reich (Münster 2003), S. 202-207. 
Ist es der Vater, der seinem Sohn Gestalt gibt, oder der Zwang des Stockes, oder ist es der Schulmeister, der ihn belehrt?

Schmerz für Herz und Zunge ist, was einen Kundigen(?) erzeugt. wird,

Das Feld, das seine Erzeugnisse hervorbringt, die ein Bassin(?) erzeugen

Ist es ein Sprießen(?) des Saatgutes, das es(?) ihm erzeugt?

Was für eine Vorbereitung(?) ist es, die ein Starker einsetzen(?) kann?

Was sind die Netze, die Fallen aus echtem Lapislazuli?

Ist es ein Vater, der sie anleitet, oder ist es ein Weiser, der unterrichtet?

(B02, 1/1) Die Wildtiere und die Vögel, ihnen wird eine Lehre zuteil; was für ein Kapitel ist es, das sie gelesen haben?

Das Wild, das auf den Bergen ist, hat es keine Anleitung?

Das Kapitel und das Schreibgerät sind der Fall, der darüber Macht gewonnen hat.

Wenn es derjenige, der [...] wäre, der sie nach vorn zum Lob kommen läßt, [...] mit Amuletten,

dann ... ... ... ein Esel(?), das Tier, das zuerst Texte kopiert(?) hat. ${ }^{19}$

Der Große der Fünf(?) ist es, der unterrichtet; (B01, 1/10) Thot(?), das Herz des Re, ist es, der Wissen gibt.

Sie kommen aus der Gebärmutter hervor, indem es mit ihnen ist, das schöne Amt des Wesirs.

[...] der es in den Leib gegeben hat, indem es leer ist im Inneren des Eies.

Sie [bestellen (?)] das Feld, während die Lampe in ihrem Herzen ist, während sie ein lebendes Abbild dessen an der Spitze von Heseret sind.

Ihre Geburt ist vor ihnen im Ausspruch des Göttlichen, das Brot und Bier vor dem ...

(B02, 1/10) Alle ... ist, worin sie sind; das Herz des Re ist es, das Kenntnisse gibt.

Die dem ... Zugehörigen, seine Söhne des Wen-Ima sind es, die er erhöhen wird in seinem Amt(?).

Derjenige unter ihnen, dessen Herz Seschat beseitigen wird, und den die Anbetungen des Isden fangen werden, ist?

Ist es ihm möglich, sich hinter sie zu begeben? Ist es sein Herz, das auf ihnen

Das ist die Sammlung der Buchrollen, indem sie geeignet zur Lehre sind, indem sie ein Speicher des Bücherhauses sind.

(B01, 2/1; L01, 1/1) Man öffnet die Front eines dieser geheimen Kästen, ihr Handwerker ist es, der ihrer kundig ist.

Wenn ein Schreiber einen Kasten auf dem Lager öffnet, sind seine Bücher neben ihm versammelt.

19 Vgl. zu L01 (V), x+3, 21. 
(B02, 2/1) Wenn ein Weiser auf ... steigt, sind die Buchrollen rings um ihn ausgebreitet."

Er-hat-die-Seelen-gefangen sagte: „Dient man nicht dem, der ein Kundiger sein will, damit er kein Handwerker sein wird?

Die Weisen, die früher entstanden sind, hatten sie nicht einen zweiten ${ }^{20}$ Körper?

Gehilfe, komm vor den Lehrer! Öffne seinen Mund mit der Lehre dessen mit wissendem Leib!

Beuge dich vor dem Schreiber, schreib ein Buch, rezitiere einen Ausspruch, eile zum Befragen des Kundigsten in seiner Zunft!

Höre die vortrefflichen Worte, sei lieblich an Zunge, (B01, 2/10) sei eifrig unter den Eifrigen! ist.

... ... ... Schriftzeichen, ein Handwerker des ..., der mit seinem Arm stark

(L01, 1/10) ... sagt ,Frau' zu den auserwählten (Sprüchen)!

Ein ...... des Horus, indem sie die Jugend großziehen in einem Übermaß an Herzensbeschwörung,

(B02, 2/10) Indem sie ... schlagen, indem sie den Starken brechen, indem sie den Handwerker bezwingen, der gehandelt hat.

Sein [...] wird die Finsternis eröffnen ...., und Millionen verneigen sich vor ihm.

Seine Liebe ist in jeder Kammer der Finsternis, seine Lehre wird ihm die Fackel anzünden.

Wenn er ... die Ewigkeit zu verbringen, [...], wird man seine Knochen verbrennen.

Man wird auf seine Lippen speien, man wird sein Fett entflammen.

Es wird in seinem Herzen schwach werden, einzutreten in die Kammer, die seine Ohren(?) versengt hat.

Wenn er es wert ist, ..., werden die Fackeln vor ihm eilen.

(B01, 2/20; B02, 3/1) Er wird Nardenö $\left.\right|^{21}$ an ihre Kerzen geben, neue Stoffe an ihre Dochte.

(L01, 1/20) Sobald ihn der empfängt, der gekommen ist, wird er herumtasten in den Gemäuern des Herrn der Heden-Pflanze.

Beschwöre sein Herz; möge sich seine Leichtigkeit entfernen, möge es schwerer als Granit sein!

Möge er Sandalen an seine Füße ziehen, möge er sich gürten in der Finsternis, möge er das Licht seines Lebens vergessen!

20 Eventuell auch als "minderwertig“ zu verstehen.

21 So übersetze ich das ägyptische tšps an dieser Stelle um des Stils willen ohne Anspruch auf botanische Genauigkeit. 
Möge er das Ruder des Ruderpfostens(?) mit dem Arm packen, möge er die Hand am Griff(?) festmachen!

Möge er segeln auf dem Meer des Netzes(?); möge er rudern auf dem Fluß der Holzkohle!

(L01, 2/1) Vereint mit(?) dem Haus der Seelen, möge er(?) sich den Speicher der Geister ergreifen.

Möge er seine Kehle eröffnen, möge er für sie die Namensreiche anbeten, die Behausung der Seelen!

Möge er die Zahl der Fälle des Rufens zum Portal(?) der großen Mutter der Abschriften kennen!

(B02, 3/10) Die Lehre ist ihm voll geworden, möge er auf den Stern schauen, möge er den Kosmos des Himmels bei Nacht anschauen!

(B04, 0/1) Mögen seine Finger arbeiten am Haus des Löwen, des Einzigartigen, des ,Starken auf dem Dach', ${ }^{22}$

bis er die Kontrolle über Auge, Ohr, Herz, Zunge, Hand und Fußsohle findet,

und er kennt ,Erkenntnis', ,Ansehen', ,Annalen', ,Erziehung', ,Erklärung', $\ldots$ und ..., ${ }^{23}$

und er trinkt ${ }^{24}$, Anordnung', ,die Anbetungen', ,Lobpreis', ihren Vater, der mächtig ist,

und er findet das ,Geheimnis', und er (B01, 3/10) erklärt die Anbetung, und er wird Gehilfe der Majestät des Thot."

(L01, 2/10) Der Weisheitsliebende sagte: „Was ist die Klaue, welche die Zunge ergreift? Oh du mit auserwählten Worten, eröffne die Geräte!

(B02, 4/1) Möge man mir die Amme nenne, welche zur Sprache ernährt, daß ich an ihren Brüsten sauge!"

Er-sprach-in-Heseret sagte: „Nimm dir das Portal, welches die Seelen bewacht $!^{25}$ Bete es an, möge es dir antworten!

Dein Lautmachen deiner Stimme bedeutet sein Lieben; dich zu hören, sein eiliges Kommen zu dir.

Wenn du sie anbetest zu Beginn des Jahres, wird die Mächtige(?) dir antworten.

Wenn du sie verstanden hast und dich auskennst, sie anzubeten, wird sie ihren Sitz in deinem Magen einnehmen. ${ }^{26}$

22 Bezeichnung des Wasserspeiers in Löwenform.

23 Die Substantive dieses Verses sind alle so determiniert, daß sie als Buchtitel bzw. -kategorien markiert sind.

24 Variante: "sättigt sich an“.

25 So in L01, 2/12. Variante in B02, 4/2: „Nimm dir die Mächtige(?), die mit Seelen beladen ist".

26 Dieser Komplex von Herz und Magen erinnert auffälig an eine Formulierung wie "Der Gott ist das Herz, seine Kapelle ist in seinem Magen “ auf dem Wiürfelhocker des Neb- 
(B04, 0/10) Öffne die Tore deines Herzens(?) vor ihr, stimme für sie 120 an, dann hört sie.

Das ist die Art der kleinen Zahl, auf welche der Schakalsherzige hört, und sie liebt ihn. ${ }^{27}$

Es mißfällt ihr nicht, ihrerseits anmaßend zu sein zum Hundsschakal, und sie haßt, ihm zu antworten,

und er ruft zu ihr 7077 Mal und sie kommt nicht auf seine Stimme.

(B02, 4/10; L01, 2/20) Sie blickt nach hinten bei ihrem Kommen(?), sie bringt Millionen zu Ende; diese bringen sie nicht zu Ende.

Dein Fragen nach ihr bedeutet ihr Kommen zu dir in Eile; in deinem Moment, wenn du sie suchst, wirst du sie finden."

Der Weisheitsliebende sagte: „Was ist das Schreiben, was sind seine (B01, 3/ 20) Wohnorte? Vergleiche es vor mir mit Seinesgleichen!"

Er-sprach-in-Hesrech sagte: „Die Schrift ist ein Meer, ihre Binsen sind das Ufer; pflüge darin ein klein wenig!

Erhebe die Binse, zähle die Bassins(?) in ihm; seien es Millionen, ermatte daran nicht,

(L01,3/1) bis sein Herr $^{28}$ dich darin schwimmen läßt, und es vor dir ganz in Fahrtwind kommt.

Die sieben Binsen, die dem Pflug gleichen in den sieben Feldern des Wissenden der beiden Länder,

(B02, 5/1) des Bauern, welcher dasteht, indem er bei ihnen als Ammenmeister(?) ${ }^{29}$ agiert, indem er die Bassins(?) befruchtet mit seinem Zwanzigstel Gerste,

sein Saatgut, das in diesen Schalen ist, die markiert und mit einer dicken Mauer abgegrenzt sind,

(B04, 0/20) das zweite Glied unter ihnen, das für sie der Herr ist, das sind die schwarzen - Variante schwarz-roten - Felder, die man nicht erreichen kann.

Diese Schalen, sie fließen über von Holzkohle; ihr Henkel(?), er arbeitet.

Wer sich zu ihnen hinbegibt, ohne Hitze erfahren zu haben, dessen Finger versengt ihre Glut.

Das gute Berechnen, das im ,Haus des Machens' (d.h. Palette) ist, dessen richtiger Name ist ,Schreibpalette.

Netjeru Kairo CG 42225, e 11; s. K. Jansen-Winkeln, Ägyptische Biographien der 22. und 23. Dynastie, ÄAT 8 (Wiesbaden 1995), Band 1, S. 122; Band 2, S. 498. Auch Amenemope 3, $13 \mathrm{f}$, wo man die weisen Worte in den Leib aufnehmen soll, damit sie im Herzen eine Türschwelle bilden, steht recht nahe.

27 So in B02, 4/7. L01, 2/17 weicht deutlich ab und ist wohl als „Das ist die Art der kleinen Zahl, auf. welche sie hört, der kleine Hundsaffe, den sie lieben wird“ zu verstehen.

28 Variante "seine Herren".

29 So wohl nach L01, 3/3; B01, 5/1 hat "Hirte“. 
Es sagt mir: ,Ich bin im Unrecht; ich kann die Erntesteuer nicht bezahlen, und auch kein anderer wird sie aus mir herausbringen.

(L01, 3/10) Seit dem Jahr 1 des Ptah-Tatenen, ${ }^{30}$ indem er halb im Nun ist, ohne daß er mich überflutet hätte. ${ }^{31}$

Derjenige, der seine ... Äcker zu bestellen verpachtet hat in seinen auserwählten Namen.

(B02, 5/10) Die Menge des Unkrauts in diesen Hochfeldern ist die Menge des Fruchtertrags.

Wer sie erntet, ist es, der die Erntesteuer für das Hochland zahlt; ihr Ertrag besteht darin, daß man es erntet."

(B04, 1/1) Der Weisheitsliebende sagte: „Möge man mir die Arbeit des Charakters sagen, die Hand, welche die Seelen des Re bearbeitet!“

Er-sprach-in-Heseret sagte: „Deine drei Finger, leg die Binse zwischen sie! Deine zwei, mögen sie ein Auflager(?)bilden!

Leg das Vierzehntel des Großen der Fünf Thot zwischen sie, vom Mund an vor deine Finger!

Sei schön mit der Hand, kopiere mit deinen Fingern, beweg hin und her, befestige und steuere!

Jeder Brief - sein schöner Anteil ist das Kopieren der Sammlung der Anbetungen, indem sie rasch sind.

(B02, 6/1) Jedes Schreiben - ihre Kraft ist eilig, ihr Steuern hastig, kein Verweilen.

(L01, 3/20) Der Weisheitsliebende sagte: „Was ist seine Art? Was für eine Form der grünenden Pflanze, oh Vortrefflicher an Liebe?"

Er-sprach-in-Heseret sagte: „Man nannte ihn ,die Binse', d.h. die Binse des Lebens, die zu berühren das Land landen wird.“

Der Weisheitsliebende sagte: „Möge man mir die Worte ${ }^{32}$ zuweisen, welche Kenntnis erzeugen, dann will ich sie $(B 04,2 / 10)$ in meinem Fleisch schwängern!

Öffne mir den Brunnen, der mit den Weisen vereint, dann will ich von seinem süßen Wasser trinken!

Die Amme, welche Aufwärterin für den Weisen ist, möge ich zu ihrem Türpfosten eintreten!

(L01, 4/1) Siehe, mein Mund ist offen, möge man ihm Milch geben, so daß sie ihren Platz in deinem ${ }^{33}$ Magen einnimmt!"

30 D.h. seit Beginn der strukturierten Zeit überhaupt, wenn man das Schema des Manetho, Fr. 3 u. 4 zugrunde legt, das Hephaistos (d.h. Ptah-Tatenen) als ersten König Ägyptens kennt.

31 Hier scheint der Acker als sprechend vorgestellt.

32 Variante: „Die Maße ${ }^{\alpha .}$

33 So die Handschriftenüberlieferung, man würde "meinem“ erwarten. 
Er-sprach-in-Heseret sagte: „Komm, dann belehre ich dich über [die Kunst(?)] des Abschreibens, die Thot seinem Gehilfen zur Hand gegeben hat!

Schreib wenig, befrage den Weisen, enthülle nicht, [was du erfahren hast(?)!]

(B02, 6/10) Frag den, der kleiner als du ist, liebe es, die Stimme des Weisen zu hören, [...] nicht!

Sei nicht gierig(?) nach Kunde, nimm reichlich Schutz, sei nicht bekümmert im Herzen, weil es gilt, ihr Äußerstes zu erreichen!

Sei besorgt um Morgen, sei bekümmert um seinesgleichen, sag mir all dein ...

Sei gesetzt und hartnäckig, sei dauernd beim Lernen [...]!

Erzeuge keine Verzögerung(?) bei der Arbeit des Briefeschreibens [...]!

Alle Arten von Schwierigkeiten, (B04, 1/20) die von verschiedener Form sind, ohne [...]

(L01, 4/10) Schau oft, handle oft, hör oft [...]!

(B02, 7/1) Komm, dann will ich sie dir beibringen, die vier Bande des Lebens, mit denen [es] gebunden ist!

Vertraue auf den Gott, lehne dich an das Gesetz, erwidere korrekt, geh nach der Wahrheit!

Sei bescheiden, denk nach, sei ein guter Mensch, enthülle nicht, was du gehört hast!"

(B04, 2/1) Der Weisheitsliebende sagte: „Oh möge deine Kenntnis sich verjüngen im Haus der Dokumente; man erzeugt sich deine Lehre! ${ }^{434}$

Du warst für mich ein Handwerker, du hast mein Leid gemindert, du hast mich in meinen Gliedmaßen dastehen lassen.

Du warst für mich ein Bauer, indem ich wie ein Feld war, indem ich es Wert war, daß du mich zum registrierten Acker machtest.

Man gab mich dir, als ich ein Klotz war, du öffnetest mich zur Statue, du wurdest mir ein belebender Schnitzer.

Du tatest mir meine Zunge auf, du hast mir den Weg eröffnet, du hast mir die Stellung gegeben.

Du hast $\mathrm{Ha}$ auf mich verringert und Liebe zu mir gebracht, du hast meine Gunst alt werden lassen.

(B02, 7/10; L01, 4/20) Du hast mich zum Alten werden lassen, während ich jung war, so daß ich die, die älter als ich sind, in deiner Angelegenheit ausschicken konnte.

Du hast mir die Stellung gegeben, als ich noch ein Kind war; ich machte es mir bequem, während die Großen dastanden.

du hast mich reich an Nachwuchs(?) gemacht, während ich allein gewesen war, du schufst mir eine Jungtruppe an Kindern.

34 Variante „zu den Kindern der Lehre“. 
Du gabst eine Flamme mit deinem Mund, (B04, 2/10) Speise eröffnete sich mir, die Dinge deines Leibes überfluteten mich.

Leicht wurden mir die Dinge, du hast für mich gehandelt, so daß ich ein lebendes Abbild war, das in Ewigkeit dauert.

(L01, 5/1) Ich werde als Statue vorne dastehen, ich werde ein Denkmal sein, indem ich ein Abbild vor seinem ... sein werde.

Ich werde deinen Dämon vergessen, ich werde deine Lehre preisen, ich werde deinem guten Namen huldigen.

(B02, 8/1) Ich werde dir danken vor dem Heiligtum des Ptah beim Fest des Imhotep in Anwesenheit von Osiris Neferhotep.

Ich werde deinen Namen am Leben erhalten zur Seite des lebenden $\mathrm{Ba}$, ich werde deinen Ba vor den Bas seiner Großen(?) vergöttlichen.

Ein Königsopfer für deinen Ka beim Altar(?), Anbetung deines Namens bei den Abbildern.

Komm doch, der du lebst als Handwerker des Isden, Gepriesener des Herzens des Re, möge er deine Aussprüche(?) bewirken.

Ich will dir danken, ich will deinen Namen frisch halten, ich will deinen Ba vor (dem) meines Vaters eintreten lassen.

Ich bin bei dir als Erbe wie ein Sohn des Wesirs, deine Lehre soll mir als Amme dienen.

Du hast mich mit dem Ausstrecken der Hand eingefangen, oh du, der mich schuf, so daß ich Thronerbe deiner Erziehung wurde.

Nachdem ich ein Kind gewesen bin, möge mein Name dauern, möge ich unter $(B 04,2 / 20)$ die Kundigen eintreten!

Möge man mich auf den Weg der Seelen des Re geben, die Weisen der ersten Urzeit!

(B02, 8/10) Ich habe mich mit Wissen vollgerafft, ich habe mich als Monument versammelt, und ich bin eins geworden mit den Gehilfen!

Ich habe die Aktion des ... des Nennens meines Namens in der Finsternis gemacht, während ich mit den Seelen kämpfte.

Möge man mir die Straßen des Gehens zum Per-anch öffnen, so daß ich mich vor Seschat auf meinen Bauch werfe!

(B04, 3/1) Möge man mir den Weg des Wandelns öffnen, möge ich den Pfad mit meinen Sohlen beschreiten!

Ich habe die Beliebtheit des großen Gottes, des Herrn der Heden-Pflanze erblickt, ich habe die Anbetungen dessen nachgeahmt, der vorne Schwingen hat.

Ich habe den Ibis auf seinem Kraut erblickt, der das Land mit seinen Klauen geordnet hat.

Ich habe den Pavian gesehen, der mit der Schlange vereint ist, der das Land mit seiner Setzwaage gerichtet hat.

(B02, 9/1) Ich habe die Vogelfalle der Majestät des Isden erblickt, ich habe die Geheimnisse des Thot gepriesen. 
Ich bin eingetreten in es, die Eierschale(?) der Ibisse insgesamt, ich habe mich zum Platz der Diener des Thot begeben.

Ich habe das Himmelsgewölbe gesehen, geöffnet ..., das Geviert der Erde bis zu ihrem Ende.

Ich wandte mich um vor den Ländern, ich kontrollierte mich in ihr, die Geheimnisse der Anbetung ihrer Ammen(?).

Mein Herz sagte mir: ,Tritt ein in sie, die Kammer der Finsternis, um zu lernen, sie auszuspähen!',

und ich werde gehen, vor dem Herrn der Heden-Pflanze anzubeten, den Boten zu küssen (B04, 3/10) vor Seschat,

(L01, 6/1) und ich werde meine Hand ausstrecken zu dem dreimal Großen, Lobpreis für den Ibis, der die Schildkröte niedertritt, ${ }^{35}$

und ich werde [...] Speise(?) für den Herrn der Schrift, [...] die Weisen, ${ }^{36}$

und ich werde die Schulter beugen mit der Schrift des großen Gottes, ziehen zum edlen Fall des Wesirs.

(B02, 9/10) Möge ich in sie gehen, die Kammer, die gepriesen ist, und du mich die Art dessen finden lassen, was in ihr ist,

so daß ich die Großen und die Kleinen sehe; Gehilfen folgen Vorstehern unter ihnen, ${ }^{37}$

so daß ich die Kammer der Finsternis sehe, eingedrungen in ihre Gestalt, das fähige Glied der Unterwelt(?).

Mein Herz sagte mir: ,Geselle dich ihr nach, der Vortrefflichen in der Kammer der Finsternis! ${ }^{\text {38 }}$

Ich flehte zu seiner Majestät mit lautester Stimme, ich eröffnete den Charakter vor der Barke des Re. ${ }^{39}$

(L01, 6/10) Ich betete das Abbild des Gehilfen des Röstens(?) an; mein Herz sagte mir: ,Lausche der Stimme! ${ }^{40}$

Ich schmückte mich mit ihnen, meinen Schmuckstücken, ich kämpfte in der Kammer der Finsternis.

(B04, 3/20) Ich ergriff die ... der Seschat, die Eröffnerin des Verborgenen für die, die in ihren Haufen sind.

(B02, 10/1) Ich entfernte mich(?) von ihnen, ich gelangte an ihr Ende, ohne unkundig zu sein des Schutzbuches ihrer Worte(?)."

35 Hier dürfte eine Anspielung auf TB 161 vorliegen.

36 Dieser Vers ist in $\mathrm{B02}$ ausgelassen.

37 In B02, 9/11 stark abweichend "Gehilfen mit überlegendem Mund sind unter ihnen“".

38 So die Lesart in B04, 3/16 f ; B02, 9/13 hat ${ }_{n}$ Kammer der Vortrefflichen“, was auch als Schreibung für ${ }_{n}$ Kammer des Jenseits“ gedeutet werden könnte.

39 In B04, 3/17 ganz abweichend „Ich habe mich hinbegeben zu seiner Majestät, meine Stimme war laut, ich habe die Kehle atmen lassen vor der Barke des $\mathbf{R e}^{\text {“. }}$

40 So nach B04, 3, 18-19. In B02, 9/15 eventuell als "Ich betete sein Bildnis an als Gehilfe des ..., ich sprach, als er Lobpreisungen formulierte.“ 
Er-sprach-in-Heseret sagte: „Sei begierig auf diese, oh Weisheitsliebender in der Finsternis! Meister der Seelen des Re ist ein (B04, 4/1) kundiger Ibis.

Er machte die Formen(?) von zehn oberägyptischen Geierinnen, indem er der Lehre dankte.

Er schuf neun unterägyptische Geierinnen mit ihren neun Jungen, indem sie den Seelen des Re huldigen.

Er leitete sein Herz; seine Finger wirkten fähig für ihn, die Abgründe seiner Ohren öffneten sich.

Seine Udjat-Augen sahen auf dem Weg voraus, er leitete auf dem Pfad der Geister. ${ }^{41}$

(L01, 6/20) Die Zeichen enthüllten ihre Gestalt, er rief ihnen zu und sie antworteten ihm.

Er erkannte die Art des Sprechens der Paviane und der Ibisse.

Er brach den Kampfplatz auf bei dem Pfad des Hundes, er war ihres Gekläffs nicht unkundig. Wesirs.

(B02, 10/10) Er erkannte das Gebell von jenen und diese Flehlaute des

[...] des Ibis, der sie aufziehen wird wegen(?) [....$^{42}$

(L01, 7/1) Er erschuf die vier Stimmen des Tierreiches(?), indem es ..., er erkannte es, er brachte es vor mich.

Weisheitsliebender, steh auf, fang sie ein, die Zaubereien des Neb-Hetep [...] der Toren! $!^{43}$

Er erschuf die Gedanken des Esels, [...] (B04, 4/10) jeden Wegführer zum Stall. ${ }^{44}$

Er öffnete den Pfad dessen, der den Gott angebetet(?) hat [...], er verengte(?) das Geheimnis der Geheimnise.

Verkünde den Weg vor ihm, geh [auf dem] Weg [...]!

Vereine dich(?) mit der Finsternis [...] Herz.

(B02, 11/1) Er wird zum Lebenshaus gehen, er wird einfangen [... Zaub]ereien."

Er-hat-die-Gedanken-geschaffen sagte: „Der Pfad des Hundes [und ...] sind die Orte des Gehens zum Lebenshaus.

41 L01 hat hier einen zusätzlichen Vers, von dem nur „[...] die Seelen des Re beschriften $[\ldots]^{\prime \prime}$ erhalten ist.

42 Dieser Vers ist in B02 ausgelassen.

43 Gegen Zauzich und Jasnow liegt hier keineswegs ein Sprecherwechsel vor, sondern ein eingeschobener Anruf. Die Lesung des bereits B07, 3. 9; B06, 1/15 u. ö. am Beginn der Komposition genannten Nebhetep ist nicht ganz sicher.

44 Es wäre zu überlegen, ob es hier eine Verbindung zu dem änigmatischen Eseltext gibt, zu dem vorerst J.F. Quack, Einführung in die demotische und gräko-ägyptische Literatur (Münster 2005), S. 127 zu vergleichen ist. 
Diese Hunde, diese Schakale, diese Paviane, diese Schlangen, die mit ihrem Mund ankündigen, ${ }^{45}$

\section{[...] \\ (L01, 7/10) Der Riegel aus Fayence [...], diese Löwen und Jubelaffen(?)}

Das Leben, das im Skarabäus wächst, der aufgehende Stern [...]

Die Fransenbinde, die am Haus steht [...] leben, denn es ist das Lebenshaus.

Derjenige, der geboren hat, wenn er .[...] $(\mathrm{B} 04,4 / 20)$ das ist sein Freund(?).

Diese Pylone aus Erz, diese [...] sind die [...] an den Mündern.

Eine Tür des Falles ist es, das zu ihnen tritt [...]

(B02, 11/10) Ein Schlüssel des Fragens(?) ist es, der sie öffnet, seine Balken schützen(?) [...] dich“46

Der-Öfner-auf-seiner-Standarte sagte: „Der Weg (?) der Wölfe ist es, der auf $[. .$.$] , der dekretiert hat(?).$

[...] tritt ein(?) zu den Türpfosten mit [...], dann siehst du Seschat(?) in [ihrem] Inneren [...] Zunge des Atum(?).

Zähle das Herz des Re, sei offen zu mir, sei nicht [...] zu mir, dem Öffner auf seiner Standarte!

(L01, 7/20) Mögest du mir die Udjat-Augen enthüllen [...] ihre ... “47

"Ich bin gekommen in deiner Gest[alt(?) ...]“"

„Wer ist es, der zu den Toren tritt [...]?“

„Oh Wächter der Kinder [...]!

Oh du Vorsteher(?) des Speichers der beiden Länder [...]!

(L01, 8+9/1) Oh Kommandant(?) der Hirten, der [...] Geschmack!

Oh der, vor dem die Balken und Pforten sind [...] Götter!"

Der Öffner auf seiner Standarte sagte: „Wer [...] wem, indem er ruft und hört?"“

Der Weisheitsliebende sagte: „Ich bin es, der das Haus geöffnet hat [... um zu] sagen die Anbetungen des Weges vor ihm."

45 Unsicher, ob am Versende noch etwas fehlt.

46 Die Zeilenenden dieser und der beiden folgenden Verse sind anhand der drei Versenden angesetzt, die auf dem Fragment vor B02, Kol. 13 erhalten sind; ihre Zuordnung ist nicht völlig sicher.

47 Ich gehe hier aus inhaltlichen Gründen von einem mehrfach unmarkierten Sprecherwechsel aus. Es scheint hier eine fast stichomythische Abfragerei mit dem Kandidaten zu geben, die an Initiationsverhöre älterer Texte (insbesondere in funerären Zusammenhängen überliefert) erinnert; vgl. hierzu J. Assmann, Tod und Initiation im altägyptischen Totenglauben, in: H.P. Duerr (Hrsg.), Sehnsucht nach dem Ursprung. Zu Mircea Eliade (Frankfurt 1983), S. 336-359; allerdings würde ich hier im Sinne von A. von Lieven, Book of the Dead, Book of the Living, in: St. Seidlmayer (Ed.), Religion in Context. Imaginary Concepts and Social Reality, OBO, iDr. hinsichtlich eines primär funerären Zusammenhangs teilweise skeptisch sein. 
Der Öfner auf seiner Standarte [sagte: „Wie war der Weg], den du zum Per-Anch zurückgelegt hast in der geballten Finsternis?"

Der Weisheitsliebende sagte: „Die Ältesten der Wölfe waren es, die mir den Weg [geöffnet haben], die fähigen Ibisse, die mich ausgeschickt haben."

Der Öffner auf seiner Standarte sagte: „Was für ein Geschenk ist es, das du ihnen dargebracht hast? Was ist dein Lobgesang (?), den sie sich angeeignet(?) haben?"

Der Weisheitsliebende sagte: „Ein lauteres Herz und [...], welche dem süßen Geschmack gleichen, der nicht vergehen kann."

Der Öffner auf seiner Standarte sagte: „Was für ein Türhüter ist es, der dich angemeldet hat? Was für ein Aufwärter ist es, der dein Geschenk empfangen hat?"

(L01, 8+9/10) Der Weisheitsliebende sagte: „Geierinnen, Schlangen, [...] Glieder, Männer(?) welche hören."

$(B 02,13 / 10)^{48}$ Der Öffner auf seiner Standarte sagte: „Opfer und Libationen $[\ldots]^{\text {«49 }}$

Der Weisheitsliebende sagte: „Was für ein Schutz ist es, in dem sie sind? Denn es ist wert, dich ihnen anzuvertrauen.

Der Öffner auf seiner Standarte sagte: „[... das Her $] z$ eines .... die Seele eines ...

Du hast angebetet, du hast rezitiert; was ist deine Gestalt? Welches sind Leder und Haut?" 51

Der Weisheitsliebende sagte: „Der Knochen eines Geistes und das Herz eines Esels, die edle Gestalt von Herz-Zunge."

Der Öffner auf seiner Standarte sagte: „Du hast dein Leben ins Gleichgewicht gebracht, du hast deinen Platz erklommen; deine ganze Gestalt, möge man mich sie kennenlernen lassen!"

Der Weisheitsliebende sagte: „Denken, Beschirmen, Erwägen, Erziehen, Beraten, $(B 04,5 / 1)^{52}$ sich auf die Wahrheit Verlassen. " 53

48 Das Oberteil der Kolumne ist verloren; die in der Edition als 13 gezählte Kolumne wäre eigentlich als $12 \mathrm{zu}$ zählen (und auch alle folgenden um eine vermindert), was ich hier nicht durchführe, da das Risiko von Mißverständnissen zu hoch ist.

49 Dieser Vers fehlt in einer Handschrift.

50 Dieser Vers wird teilweise zur Rede des Offners auf seiner Standarte gezogen.

51 In einer Handschrift wird erst zu Beginn dieses Verses wieder der Öffner auf seiner Standarte als Sprecher eingeführt.

52 In der Handschrift B04 fehlt tatsächlich eine Kolumne zwischen der in der Edition als 4 und der als 5 gezählten.

$53 \mathrm{Ab}$ diesem Vers ist für einige Verse ein neues Fragment des pCarlsberg 616 relevant, dessen Kenntnis ich Kim Ryholt verdanke. 
Der Öffner auf seiner Standarte sagte: „Komm, dann erziehe ich dich, bevor du gequält wirst, bevor du in die Hürde(?) ${ }^{54}$ eintrittst."

[...] deine Angelegenheiten, vollende das Hören [...] Licht für die Seelen, welche die Lehre lieben.

[...] zum Ort, zu deinem Herz, das geleitet hat zum Platz [...] Kundige mit dir als Toren.

$(\mathrm{B} 04,5 / 5)[\ldots]$ in der Erde in $[\ldots]$ der Aufgangsstätte des [...].

$(\mathrm{B} 02,14, \mathrm{x}+1)[\ldots]$ große, um zu machen die [...] es [...] deine Knochen.

[...] schlagen [...] verzehren mein [...], ${ }^{55}$ das Fett meines ${ }^{56}$ Fleisches.

[...] die Lehre in meinen Gliedmaßen, dem ... mit vortrefflicher Kraft.

Mein Fleisch(?) [...] das Herz(?) [...] Art meiner Glieder.

(B04, 5/10; C02, 1/1; L01, 10/1) Siehe, die Eingeweide, welche Fett an die Glieder geben, ... [...] Münder! leben!"

Siehe, ich stehe da, indem ich einer Mumie gleiche, indem ich ... [...]

Der Öfner auf seiner Standarte sagte: „Ist es die Lehre ${ }^{57}$ des Vaters, oder das Wissen der Kundigen, oder des Wissenden der beiden Länder?“

Der Weisheitsliebende sagte: „Die Netze der Schentait (und) Seschat haben mich eingefangen, das Schlagnetz der Seschat hat mich erjagt."

Der Öffner auf seiner Standarte sagte: „Was ist der Geschmack der Rezepte der Schrift? Was ist ihr Netz?"

Der Weisheitsliebende sagte: „Ich habe alle Rezepte erprobt, die vergehen; ich habe alle Geräte gesehen, die müßig sind.

Siehe, Salz erregt das Fett nicht so wie die Anbetung des Taiti.

$(B 02,14, x+10)$ Ein ... tritt nicht so auf den Ton wie die Kenntnisse dessen mit denkendem Herzen.

Das ... des Beilagers fängt nicht so ein wie die Liebe $(\mathrm{B} 04,5 / 20) \mathrm{zu}$ den Abschriften."

(C02, 1/10; L01, 10/10) Er-sprach-in-Hesrech sagte: „Drei Meere liegen zwischen ihnen, den Gängen dieses Landes.

Hast du in ihren Fähren übergesetzt, hast du ihre Kanäle genommen? fen?"

Hast du ihrem Fährmann den Lohn gegeben, hast du ihre Taue(?) ergrif-

Der Weisheitsliebende sagte: „Ich habe ihre Schiffe(?) betreten, ich habe ihre Fische gefangen, ich habe die fettesten ihrer Vögel erjagt.“

Der Öfner auf seiner Standarte sagte: „Es mag sich ereignen können, daß (B04, 6/1) du das Ritual der Kammer der Finsternis zerschnitten hast.

54 Oder "das Allerheiligste“.

55 Dem Determinativ nach ein Körperteil.

56 In einer zweiten Handschrift wohl fehlerhaft „seiner“.

57 Variante "Initiation". 
Hast du die Kanäle durchrudert? Was ist ihre Natur, ihre Gestalt?"

(B02, 15, 1) Der Weisheitsliebende sagte: „Ich habe die Küche(?) des Meeres der Gehilfen durchrudert mit dem Ruder der Arme des Schu.

Ich habe mich umgewandt zur Fähre der Schlange, welche die Schriftwerke nimmt; meine Finger ergriffen das Ruder der Feldbewohner.

Ich verbrachte drei ${ }^{58} \mathrm{Jahre}$, indem ich in ihr ruderte, indem ich in ihren Teichen fischte.

Ich zog zur Fähre der trefflichen Geister; es erhob sich für mich Streit mit ihren Seelen.

(L01, 10/20) Ich aß ihre Vögel, ich verschlang ihre Falken, ich vereinte mich mit ihren Eierschalen(?).

Ein Pavian gab mir eine Lanze von einem Sechzigstel, er sagte mir: ,Das ist ihr Ruderpfosten(?).

Ein Hund gab mir einen Block aus weißem Marmor, er sagte mir: ,Das ist ihr Fischernetz."

Ein Ibis gab mir ein Segel aus Rindsleder, während sein Mast aus Löwenleder ist.

Ein Hund gab mir $(B 04,6 / 10)$ ein Band aus Gottesworten, er sagte mir: ,Das ist ihr Jagdnetz.

Meine Glieder bedrängten die Leute des Ruderpfostens(?), mein Herz fischte für sie mit Netzen; die Zunge erjagte in ihrem Geviert(?). ${ }^{59}$

Ich richtete das Segeln Tag und Nacht fest ein, ich segelte für zwanzig Jahre in der Art der Teiche.

Ich paddelte in einem Wasserarm in den ..., ohne daß ich das Ende des ganzen Meeres erreichen konnte.

Ich konnte die Mitte seiner Schiffer nicht erreichen, um die Segler zu befragen, die bei ihm paddeln.

Sie machten mir ... im Namen seines schwachen(?) Kapitäns.

Ein Kanal war es, der sich in Eile(?) zum Ufer zurückgewendet hat; ich kenterte(?), ohne daß ich sie erreichte. Schilfs,

Sobald ich im Osten(?) des Lebens landete, dem Feld des grünenden(?)

da fand ich die Menschen, die Tiere, die Vögel, das Gewürm, die Pflanzen des .., die wuchsen,

während ein lebender Kanal sie umgab, all seine Brutvögel in seinem Inneren.

(B04, 6/20) Ich vollendete die Jahre bis zu 20 Jahren.

58 Variante einer anderen Handschrift wohl „zehn“.

59 Ab diesem Vers ist für eine Weile nur die nicht stichisch geschrieben Handschrift B04 verfügbar; die Versabteilung ist deshalb provisorisch. 
$(\mathrm{C} 02,2 / 10)^{60}$ Ein Esel sagte mir im Stall des Tänzers: ,Dies ist ein Weg der Schriftkunst(?).

$(B 02,12 / 1)^{61}$ Siehe, ich stehe im Feld der Mühsal, ich klopfe bei dir an, willst du mir nicht die Art ihres Kampfes eröffnen?"

Der Öffner auf seiner Standarte sagte: „Diese Lanzen von einem Sechzigstel(?), die zu tragen mühselig ist, hast du die Art gemacht, sie zu tragen?“

Der Weisheitsliebende sagte: „Ein mitleidiger Vertrauter gab mir die Technik, sie zu tragen; (B04, 7/1) leichte [...] sind sie."

Der Öffner auf seiner Standarte sagte: „Hat das Portal des Grünsteins es verstanden, das jeden Block aus sich gebiert?“

Der Weisheitsliebende sagte: „Ich trat in ihn ein, den Block(?) aus Türkis, welcher die Verklärten beschirmt,

wobei er offen ist zur Kammer der Finsternis; Millionen von Beschirmungen(?) bedeutet es, sie sehen zu können."

Der Öffner auf seiner Standarte sagte: „Was ist hinter ihm, was ist in seiner Mitte? [Eröffne(?)] mir die in seiner Mitte!"

Der Weisheitsliebende sagte: „Es gibt 42 Seelen in ihm, indem sie Millionen von Abermillionen anweisen.

Was sind die Auserwählten der Tiere, welche den Platz der Halle der beiden Wahrheiten $[\ldots]$ ?

(B02, 12/10) Der Öffner auf seiner Standarte sagte: „Welches ist ihre Form, enthülle ihre Art, (B04, 7/10) was ist ... den Mund öffnen ... sie hören?“

Der Weisheitsliebende sagte: „Ich werde ihre Namen eröffnen und ihre Sprache(?); denn sie sind blind gegen die Dunkelheit(?).

Es gibt sieben unter ihnen, die den Herrn des Schutzes ankündigen, indem sie ein Amulett gegen den mit finsterer Erscheinung sind.

Zwei weitere unter ihnen, die eine Stellung geben zum Weg(?) des Todes, indem sie auf Erden vorbereiten.

(L01, 11/1) ${ }^{62}$ Einer an der Spitze von ihnen, der als Lampe agiert, indem er erleuchtet, indem er ihre Sprache wiederholt.

Hinten neun Säulen, die ein Udjat-Auge tragen, welches das Pektoral(?) der beiden Länder(?) entblößt(?).

Während eine edle Geierin sie alle umarmt, welche alle Jungen gebiert, um sie einzufangen.

Ich sah ihr ... und ihren Charakter ... ... in einer Art,

60 Der obere Teil der Kolumne von $\mathrm{C} 02$ ist verloren.

61 Die in der Edition als 12 gezählte Kolumne gehört tatsächlich hinter Kol. 15. Ich behalte die vorgegebene Zählung einstweilen bei, um allzu große Verwirrung zu vermeiden.

62 Zwischen den Kolumnen 10 und 11 nach Zählung der Edition ist tatsächlich eine ganze Kolumne verloren gegangen. 
indem es aus Gold und Türkis gearbeitet ist, anderes aus echtem Lapislazuli der Halle.

Die Geierin fand ihre Jungen zwischen den Säulen, (B04, 7/20) indem sie in der Leibung der ,Finsternis' zum Vollenden war.

Ich ging zu ihr, ich sah in sie, ich vermehrte die Lobpreisungen, die vorher geschehen waren.

Ich fand die Wissende(?) - das ist die, die zuerst begründet hat, indem sie als Lampe der Kunde dient,

(B04, 8/1) wobei man ..., wobei sie ihnen Anweisungen erteilt und derjenigen befiehlt, die sie geboren hat. ${ }^{63}$

(L01, 11/10) Ich enthüllte ein geschütztes Meer, dessen Umkreis mit Türkis bewachsen war,

wobei neun Barken auf ihm auf- und abfuhren, wobei ihre „Seelen“ (d.h. Bücher) ihr Fundament waren,

ihre Binsen neue Worte hervorbrachten, ihre Wärterinnen und Ammen Ichneumone(?) waren.

Ich nahm eine Lampe in meine Hand, um das Innere des Platzes vor ihr(?) zu erkennen.

Ich gelangte in sein Inneres, ich erreichte einen Speicher des Lebens, der schwamm(?), ohne daß er sich auflöste(?).

Ich fand sechs Ruderer, die dasaßen, indem sie vereint waren, indem sie in einer Redeweise priesen,

(B04, 8/10) indem sie die Herzen vereinten mit denen von Ober- und Unterägypten zu den Ländern, welches ihre Herrin ist.

Siehe, sie haben keinen Feind, sie verbergen sich nicht, während sie eine krankhafte Fundierung niedertreten(?),

während sie ein Leiden heilen, für das es kein Buch gibt, indem sie Sünden mit ihren Aussprüchen abwischen,

indem sie einen Mann vor seinem Schicksal retten, während sein Tod hinter ihm dasteht. ${ }^{64}$

(L01, 11/20) Ihre Größe ist gepriesen, derjenige, der sie hat nehmen lassen ... von süßer Beliebtheit.

63 Die Episode von der Geierin am Eingang des Lebenshauses (B04, 7/19-8/1) erinnert dabei an die Geierinnen, die im Buch vom Fayum das Per-anch von Ra-Sehui umgeben, s. H. Beinlich, Das Buch vom Fayum. Zum religiösen Eigenverständnis einer ägyptischen Landschaft, ÄA 51 (Wiesbaden 1991), S. 127 f., Taf. 28.

64 Auch hier ließe sich eine Parallele zur Beschreibung des Per-anch im Buch vom Fayum ziehen, wo eine liegende Gestalt eines Menschen abgebildet ist, die wenigstens nach einer Version einen "verunreinigten", d. h. kranken oder moralisch unreinen Mann bezeichnet, s. Beinlich, Buch vom Fayum, S. 236 f. Z. 982, wo die eindeutige Schreibung si pw $\underline{h r}$ cbw nicht verstanden ist. 
Wirr sind ..., mühselig ihre Worte, ihre Wiederholungen sind unterschieden von der Schrift,

wobei sie selbst es sind, welche die Aussprüche auflösen; sie sind es, welche ihre Erklärung sagen werden.

Sobald sie aber schlugen, und ich die Lobpreisungen kannte, $(\mathrm{B} 04,8 / 20)$ da sprach mein Herz mir von Entzücken mit ihnen,

bis ich es fand im Charakter des Himmelsgewölbes, das nach Pe geleitet hat durch die Vorschriften,

(L01, 12/1) die Summe jeder Einzelnen von all ihren Wohltaten, die gekommen sind aus dem Geviert des Ozeans.

Es währte lange, daß ich mit ihnen saß am Speicher, indem ihre Magie mein Herz bezauberte.

(B04, 9/1) Ich fand die [...] der Stütze des Lebens, die Isden festgesetzt hat, die er denen vom Lebenshaus gab,

den Nachweis der Fälle der Magie, indem sie hinter(?) ihm als Schützer allein sind.

Die $[\ldots]$ Amt ... [...] es zählen.

[...] Amme [...] in ihnen.

[Horus] Chentechtai ${ }^{65}$ kennt diejenigen, welche vor $[\ldots$ sind ...] ihre Fähigen.

[Ich] wandte mich zum Papyrus [...] der bis zu ihrem Ende gekommen ist. Glut,

$[\ldots]$ ihr nach, ich drang ein in die $[\ldots]($ B04, 9/10) und ihr Charakter [...]

(L01, 12/10) und der, der nach ihnen riecht, ist es, der sie zu [...] bringt.

Ich eilte herbei, um ihre Knochen zu verbrennen, um zu backen(?) [...]

Ich eilte(?) zur Schlange, um zu veranlassen [...], indem die Herzen in den Mündern sind mit einem Mal.

Flechten

Sie sind in je eigener Gestalt, zahlreich ist [...] ihre Art ist erhaben, nun [...]

Ich trat ein zu ihnen, ich sah ihre [...] Ruhm.

Ich fand eine Uräusschlange, die bei ihnen war als [...]

(B04, 9/20) Indem sie Atem gebiert in einem .[...] Feld von Türkis [...]

während ihre Kinder Hundert ... sind [...]

Fünfzig wenden sich um von Gestalt zu Gestalt [...]

Einige Stiere sind unter ihnen, einige [...],

(L01, 12/20) einige Landkriecher sitzen [...].

Ferner die Geierin, die gebiert [...]

65 Ein meist falkengestaltiger Gott von Athribis, der gerade in magischen Schutzritualen eine wichtige Rolle spielt, vgl. P. Vernus, Athribis. Textes et documents relatifs à la géographie, aux cultes, et à l'histoire d'une ville du Delta égyptien à l'époque pharaonique, BdE 74 (Kairo 1978), S. 402-405. 
Verweile in ihnen, der veranlaßt hat [...]

Millionen von zwei Millionen [...]

(L01 (VT), $x+4 / 1)^{66}[\ldots]$ unter ihnen, ich machte meine Sprache fest [...]

Ich [wandte] mein [Gesicht] zu den Wassern, den Wassern, die flossen [...] ... [...]

Millionen von Kindern und Hunderttausende von Erschaffern [...]

Ich röstete(?) Keuschlamm(?) [...] ich spuckte(?) [...]

Bis mein Herz ... erkannte [...] und [meine] Finger [...]

Ich wünschte, die Erde zu küssen für die Götter des Lebenshauses, ${ }^{67}$ und daß ich [...]

daß die Kinder mir den Wunsch erfüllen, zu Fischen als Fischer und [ich] öffne $[. .$.$] .$

Möge man mich unter sie setzen, die Hirten der Hunde vom .[...]

wobei es verdient ist, mich unter sie zu setzen, die fähigen Geister [...]

(L01 (VT), $x+4 / 10$ ) Ich habe meinen Mund kosten lassen, um anzuklopfen bei den Abschr[iften ...]

Siehe, ich stehe vor $[\ldots] .{ }^{468}$

Der Öffner auf seiner Standarte sagte: „Bist [du] gegangen [...]

um zu töten den, der dir gegenüber steht, die Spitze .[...]?

Hast du das Haus des Löwen gesehen, das macht(?) [...]

Diese Hunde, diese Wölfe, diese Stiere, die [...],

diese Schlangen, diese Schlänglein, diese Körper des Gew[ürms ...],

diese Schwerter, diese Lanzen, diese Körper [...]

Diese Fliegen, die im Schatten sind, während die Häuser [...]?

Hast du die Wachtel geküßt, die in dem .[...] ist? ${ }^{\text {(69 }}$

(L01 (VT), x+4/20) Der Weisheitsliebende sagte: „Ich durchquerte(?) diese Schlachtfelder(?) [...]

Ich sah die Fliegen, wie sie den [...] zerteilten [...], ich erblickte die Geierin in ihrem Busch in dem .[...]

Ich sah den Hund, der in der Schrift [...]

66 M.E. ist Kolumne $x+4$ des "Geiertextes " vor Kolumne $x+1$ zu stellen, in jedem Fall ist sie die direkte Fortsetzung von L01, Kol. 12.

67 Diese Notiz sollte im Zusammenhang mit einer realen Auflistung der Götter des $p r-c_{n h}$ im pBrooklyn 47.218.50 16, $9 \mathrm{f}$ : gelesen werden, wo diese aus Ton hergestellt werden. Genannt werden dort ein Falke, ein Krokodil, ein Ibis, ein Pavian, ein 3s-Geier, ein Reiher, eine Ziege; sieben Götter des Lebenshauses allerdings anderer Art auch bei D. Mendel, Die kosmogonischen Inschriften in der Barkenkapelle des Chonstempels von Karnak, MRÉ 9 (Turnhout 2003), S. 124.

68 Dieser Vers ist fast hoffnungslos obskur, meine Ubersetzung geht von stark mittelägyptischen Relikten aus.

69 Für die Wachtel in Verbindung mit dem Lebenshaus vgl. Buch vom Fayum, Ed. Beinlich Z. 1107 . 
Ich erspähte das Gesicht des Asch-Tieres, während [...]

(L01 (VT), $x+1 / 1)$ [...] ...gefallen unter seinem Speer, indem er die Schildkröte auf der Sandbank niedermetzelt.

[...] Falke, der buntgefiedert ist, indem er auf dem Leib einer Oryxantilope triumphiert.

Ich huldigte [...] dem Gemehsu-Falken, indem er das rote Nilpferd ersticht.

Ich sah die ... König von Ober- und Unterägypten als Schutz der Geheimnisse.

Die Geierin(?) betrauerte(?) [...] den Nun mit Binsen(?), um das Land mit ihrer Arbeit zu überschwemmen.

Ich sah das Kupfer der Kraft, indem es [...] öffnet, indem es überströmt vom Blut der Frevler.

Ich sah die 14 Schriften der Wissenden, die wegen des Skarabäus [...] hat.

Ich verehrte die von Abutig, während sie ihren Korb(?) Gerste zerstampfte, indem sie es zerteilt für [...] Götter des(?) Königs von Ober- und Unterägypten.

Sie ließ die Dienerin der weißen und die Dienerin der roten Krone davon essen auf dem ... [...] Palastfassade.

(L01 (VT), $x+1 / 10)$ Ich sah die vom Haus [...] Schloß des Lebenshauses, ein Schlüssel aus Eisen.

Ich huldigte dem göttlichen Falkenweibchen, während es den Seelen Anweisungen gibt, während der Schreiber der Gestalt(?) mit [seiner] Hand [...] schreibt.

Eine Weihe, ein Ibis, ein Falke verteilen sie mit einem Mal auf die Länder.

Schlangen ließen sie bewachen, Uräen [waren für sie] Türhüter.

Die Türhüter fragten ${ }^{70}$ nach den Seelen des Re, die Wächter nach ihrer Natur.

Man sagte mir: ,Es gibt 42 Hügel im Lebenshaus, die bewachsen sind mit [...] Binsen.

42 Geierinnen haben zwischen ihnen geboren, indem ihre Jungen [...] $\operatorname{acht}(?) .^{6}$

Ich fragte nach den Geierinnen und ihren Namen, die Jungen sagten mir ihre Gesänge,

während eine große Geierin sie alle umarmte, wobei sie begierig(?) war nach dem Schutz,

während der Löwe bei ihrem Thron sitzt, [...], indem er festgesetzt ist zu ihrer Seite,

(L01 (VT), $x+1 / 20)$ wobei sie sagt: ,Er wird ein Gemetzel unter denen anrichten, die er töten wird .[...].

Wobei sie öffnet und er die Gabe der Schriftrollen verschließt unter [...].“

Der Öffner auf seiner Standarte sagte: „Du wirst große Begierde haben [...].

70 So die Textüberlieferung, denkbar wäre eine Korrektur zu „Ich fragte die Türhüter.“ 
Oh mögest du sie herbeiführen, daß wir sie kennen, daß wir unsere Herrin anbeten, die [...] gegründet hat!

Der Weisheitsliebende sagte: ${ }^{71}$ „Eine Geierin, die einen Bogen spannt, während ihr Junges [...] - das ist Elephantine.

(L01 (VT), x+2/1) Eine Geierin, [die] eine Waage [...], während ihr Junges aus Gold in ihrer Hand ist - [das ist Edfu].

Eine Geierin, die [...] See, indem sie Feuer wirft in der Umgebung ihres Jungen(?) - [das ist Elkab/Esna].

Eine Geierin mit ihren Jungen, indem sie die Stützsäulen des Himmels tragen [ - das ist Theben/Armant]

Eine Geierin, die [...] auf ihr Junges [... - das ist] Kop[tos].

Eine Geierin, die auf einem Krokodil [...], während ihr Junges vor(?) ihr tanzt - [das ist] Dendera.

Ein Junges [...] eine Geierin [indem] sie gut das Sistrum spielen(?) - das ist Hut-Sechem.

Eine Geierin, deren [Hand(?) an] ihrem Mund ist, indem sie wegen ihres Jungen schweigt(?) - das ist $\mathrm{A}$ [bydos] .

Zwei Gebärmütter(?) gegenüber(?) einer Geierin, während ihr Junges ... das ist Achmim.

Eine Geierin, [die] einen Stier frißt, während ihr Junges jauchzt über ihr [...] - das ist Per-Wadj.

(L01 (VT), x+2/10) Eine Geierin, die ihr Gefieder schmückt, [während ...] versammelt ist(?) für ihr Junges - das ist Scha[shotep].

Eine Geierin, deren Klaue ausgestreckt ist, während ihr Junges [...] - das ist Per[-nemti].

Eine Geierin, in deren Hand ihr Junges ist, während es das ausspeit, was es gegessen hat - das ist Assi[ut].

[x] Geierinnen, die [auf] einer Akazie [sind], während ihre Jungen im Fluß ihnen gegenüber sind - das ist Kusae.

Acht(?) Geierinnen und ihre neun Jungen; man ließ eine davon fliegen ... das ist Hermopolis.

Eine Geierin und ihr Junges, die sich auf einer Antilope brüsten - das ist Hebenu.

Eine Geierin, die einen Hund beißt, während ihr Junges ihn [schlägt(?)] das ist Saka.

Eine Geierin, welche die Schwingen mit ihrem Jungen ausbreitet, indem sie ihren Vater beschützen - das ist Hardai.

71 Eine Kommentierung und teilweise Neubearbeitung der folgenden Sektion werde ich in meinem Beitrag "Geographie als Struktur in Literatur und Religion“ geben, der in F. Adrom, K. Maurer, A. Schlüter (Hrsg.), Altägyptische Weltsichten erscheinen soll. 
Eine Geierin und ein Pferd, während ihr Junges .[...] Schild(?) - das ist Wabab.

18 Geierinnen, die einen Esel zerfleischen, [während sie] ihr Junges [...] das ist Herakleopolis.

(L01 (VT), $x+2 / 20)$ Eine Geierin, die ein Junges gebiert, um zu befestigen [...]. - das ist Semen-Hor.

Eine Geierin, die von Krankheit bekümmert ist, während ihr [Junges ...] ihr Gesicht [...] - das ist Atfih.

Eine Geierin, die den Himmel erbaut, während ihr Junges die Erde ihr gegenüber [...] - das ist Memphis.

Eine Geierin, die einen Rest von Lobpreis macht beim Vergessen ihres [Jungen] - das ist Seschem.

Eine $[\mathrm{Gei}] \mathrm{er}[\mathrm{in}]$, die mit ihrem Jungen vereint ist, indem sie tragen $[. .$.$] ...$ - das ist Per-[...].

(L01 (VT), $x+3 / 1$ ) [Eine Geierin ...] ... ihr Junges ... Wind - [das ist ...]

[Eine Geier]in mit dem Bogen, während ihr Junges nach ihr zieht - [das ist Sais]

Eine Geierin von 7000 Jahren, während ihre beiden Jungen an [ihr] saugen - [das ist Xois].

Eine Geierin auf einem Boot, während ihr Junges steuert - [das ist ...]

Eine Geierin mit ihrem Jungen, indem sie das Netz auswerfen [- das ist ...]

Eine Geierin, die Reinheit festsetzt [... - das] ist B[usiris.]

Eine Geierin, die ihren Schwanz [...] setzt nach draußen [...] ihr Junges [das ist ...]

Eine Geierin, die Strafe zukommen läßt [...] wegen [...] ihr Junges [...] das ist ...]

Eine Geierin, die in ihrem Nest aus Papyrus und Stroh(?) ist, während [sie ...] zu ihrem Jungen - [das ist ...]

(L01 (VT), $x+3 / 10$ ) Eine Geierin, die Fische fängt, die Speise gibt [...] für ihr Junges - [das ist ....]

Eine Geierin, die Wissen hinlegt für ihr Junges in [...- das ist ...]

Eine Geierin, welche die ältesten Jungen ernährt, indem sie gibt [...- das ist ...]

Eine Geierin, die einen Knaben ${ }^{72}$ zerfleischt, indem ihr Mund [...] ihr Junges [- das ist ...]

Eine Geierin, die in ihrem Nest ist, indem sie [...] Ort - [das ist ...]

Eine Geierin, die eine Fackel mit ihrer Hand anzündet(?)[...] ihr Junges, indem es ißt [ - das ist ....]

Eine Geierin, die sich in einem Schlafplatz zwischen den Schwingen des Gemehsu-Falkens ausruht [- das ist ...]

72 Oder "Syrer"? 
Summe der Geierinnen und ihrer Jungen in ihrer Spezifikation auf dem Korb(?) mit Gerste

Der König, der älteste Bruder der Schentait, und(?) Seschat, das sind die Geierin und ihr Junges.

(L01 (VT), $x+3 / 20$ ) Die Brust des Wissens, welche die Wissenden säugt, ist es, die bei ihnen als Amme ist.

Das Tier, das zuerst Wissen erlangt hat, der Esel, ${ }^{73}$ ist es, der den Weg vor ihm leitet.

Der wissende Ibis, der die Alten ausgeschickt hat, ist es, welcher der Größte der Großen ist.

Er ist es gewißlich, der für seinen Vater und seine Mutter - Variante: Vorvater - kundig gewesen ist, indem er .[..].

Mir sagend: ,Kopiere seine Kinder, dann wird er Größter derer, die größer als er sind.'

Hiermit endet der zusammenhängend erhaltene Bereich. Unter den unplazierten Fragmenten sei zumindest noch auf die mutmaßlich näher zusammengehörigen Fragmente L01.9 und L01.15 (in dieser Sequenz als Reste zweier aufeinander folgender Kolumnen zu lesen?) hingewiesen. Die darin auftretenden Stichwörter, etwa „Skarabäus“, „Zwergin“, „die acht Chnume“ ${ }^{74}$ und vor allem die vier Frösche und vier Schlangen sowie die Erwähnung der Strahlen der Sonne deuten darauf hin, daß hier eine Kosmogonie wesentlich hermopolitanischer Prägung thematisiert wird. ${ }^{75}$ Es muß weiterer Forschung vorbehalten bleiben, ob diese Passagen ganz ans Textende gehören, oder in den schlecht definierten Bereich nach der Einleitung, in die ich oben bereits versuchsweise einige Bruchstücke gesetzt habe, in denen Aktionen der Welteinrichtung dargelegt werden.

Einige generelle Bemerkungen zum Text und seinem Sinn dürften angebracht sein. Zuerst sollte die Sprache kommentiert werden. Sie ist nicht nur bildhaft und bereits dadurch schwierig, sondern zudem auch nur mit großen Einschränkungen überhaupt als Demotisch zu bezeichnen. Tatsächlich tauchen allenthalben Formen und Lexeme auf, die eher dem Klassisch-Ägyptischen oder allenfalls Neuägyptischen zuzurechnen sind. Man kann überlegen, ob bewußter Archaismus vorliegt, eine erhebliche Verwendung älterer Quellen oder eine inkonsequente Übersetzung einer generell älteren Vorlage. Ich würde eher einer

73 Vgl. Anm. 44.

74 Vgl. etwa M.-L. Ryhiner, L'offrande du Lotus dans les temples égyptiens de l'époque tardive, Rites égyptiens 6 (Brüssel 1986), S. 132 Anm. 4.

$75 \mathrm{Zu}$ Kosmogonien in griechischer Sprache mit hermetischem Hintergrund und eventuellen Bezügen zu Hermopolis vgl. K. Geus, Ägyptisches und Griechisches in einer spätantiken Kosmogonie, in: K. Döring, B. Herzhoff, G. Wöhrle (Hrsg.), Antike Naturwissenschaft und ihre Rezeption, Band 8 (Trier 1998), S. 101-118. 
der beiden letzten Lösungen zuneigen und stelle deshalb in den Raum, inwieweit das "Thotbuch" erhebliche Wurzeln hat, die bis ins 2. Jahrtausend v. Chr. zurückgehen. ${ }^{76}$

Eine stilistische Eigenheit des Textes erlaubt gleichzeitig, einen signifikanten Kontakt mit einem anderen Werk zu etablieren. Im Thotbuch gibt es Passagen, die bei den Fragewörtern eine auffällige Tendenz zu Variation zeigen, auch im Aufgreifen eigentlich rein mittelägyptischer Lexeme. Gleich zu Anfang in der Befragung des Kandidaten gibt es nebeneinander im selben Vers $n m$ "wer", $s b$ bzw. $s b b$ als Schreibung für altes $s i$ "wer, was“, sowie pry u. ä. als Schreibung für altes pw-tr "wer" (B07, 19 u. Par.). Eben dieses Nebeneinander findet sich auch zu Beginn der Hungersnotstele, wo der König den Vorlesepriester Imhotep befragt und dabei formuliert $s(b)$ i s.t msi $n h^{c} p i m(i) n w . t h(n) s k . t^{\prime} i p(t) r$ nčr wn (i) $m=f$ \#Welches ist der Geburtsort des Nil? Was ist die Stadt des Geflochtenen? Welcher Gott ist in ihm?".77 Wenn man davon absieht, daß im Demotischen nur die Form $n m$ und nicht einfaches $m$ für "wer" möglich ist, sind dieselben drei Frageworte gewählt. Eine Verbindung zwischen den Texten ist um so plausibler, als Imhotep in der Hungersnotstele ja gerade das Epitheton wn-im(3) trägt, als dessen Sohn der Kandidat im Thotbuch gilt.

Inhaltlich ist das Werk schon in den Vorberichten als "Thotbuch" und als Vorläufer der griechischen Hermetika aufgefaßt worden, und dieser Aspekt hat auch bereits Interesse von Seiten derer erhalten, die sich mit jenen Kompositionen befassen. ${ }^{78}$ Auf jeden Fall wird Thot im Text einmal als $w r w r$ wr bezeichnet (B02, 9/7 u. Par.), also dreimal hintereinander mit dem Wort "groß“. Dennoch kann die nunmehr vorliegende Gesamtpublikation die Verbindung weniger gut substantiieren, als im Vorfeld gehofft wurde. Gleich ist immerhin die Grundstruktur der dialogischen Lehre. Allerdings sehe ich (anders als die Herausgeber) keinen Anlaß, den Hauptsprecher (es gibt mehrere, s.o.) der lehrenden und abfragenden Seite als Gott Thot in Person zu verstehen. $\mathrm{Zu}$ deutlich wird dieser im Text nämlich als dritte, von den Sprechern verschiedene Gestalt behandelt (vgl. etwa B01, 1/10).

An konkreteren inhaltlichen Übereinstimmungen mit den bekannten Hermetica gibt es nicht allzu viele; vorderhand am bemerkenswertesten scheint

76 Die von den Bearbeitern (S. 72 f. u. 77) angenommene ptolemäische Entstehungszeit halte ich für distinktiv zu spät.

77 Vgl. P. Barguet, La stèle de la famine, à Séhel, BdÉ 24 (Kairo 1953), S. 16 f. u. Taf. III.

78 J.-P. Mahé, Preliminary Remarks on the Demotic Book of Thot and the Greek Hermetica, Vigiliae Christianae 50 (1996), S. 353-363; E. Hornung, Das esoterische Ägypten. Das geheime Wissen der Ägypter und sein Einfluß auf das Abendland (München 1999), S. 54; F. Ebeling, Das Geheimnis des Hermes Trismegistos. Geschichte des Hermetismus (München 2005), S. 54. K. van Bladel betont in seiner Rezension der Publikation in Brynn Mawr Classical Review 2006.05.19 (http://ccat.sas.upenn.edu/bmcr/2006/200605-19.html) die geringe Menge der Bezüge zu den hermetischen Kompositionen. 
die von den Bearbeitern (S. 70) bereits herausgearbeitete zwischen der (oben neu übersetzten) Passage über die Kompetenz der Tiere und dem Stobaios-Fragment Nr. IV (Sektion 1-3). Von Interesse sein dürfte auch der nur koptisch überlieferte Traktat von der Achten, welche die Neunte enthüllt (NH VI, Traktat 6). Dort erscheinen die frosch- und katzenköpfigen(!) ägyptischen Urgötter von Hermopolis, die auch im Thotbuch belegt sind, sowie eine Tafel aus Türkis, welche mit der Bedeutung dieses Materials in einigen Sektionen des Thotbuches korreliert. ${ }^{79}$ Insgesamt liegt der hier publizierte Text, so erstaunlich und ungewöhnlich er auch sein mag, aber doch weithin im Bereich traditioneller ägyptischer Geisteswelt - substantielle griechische philosophische Einflüsse lassen sich nicht fassen. Vielleicht mag dies - im Sinne der oben kurz angeschnittenen Datierungsfrage - auch ein Problem des Alters sein. Zwischen dem „Thotbuch“ und den griechisch überlieferten Hermetika dürften etliche Jahrhunderte realer Distanz der Komposition liegen.

Worum geht es nun wesentlich im Text? Schon der mutmaßliche Titel gibt dies im Grunde ganz gut an - es geht darum, daß eine Elitegruppe von Wissensspezialisten ausgebildet wird und Zugang zu esoterischem Spezialwissen erhält. Ziel ist eine „Kammer der Finsternis“, wobei letzteres Wort so oft im Text mit dem Determinativ der Buchrolle versehen wird, daß man sich schon fragt, ob ein Spiel mit der schwarzen Farbe der Tinte intendiert ist. Andererseits wird man auch überlegen müssen, ob hier eine Initiation in finsteren Kammern (z. B. Krypten) im Hintergrund steht. ${ }^{80}$ Dadurch mögen Phrasen wie "du hast die verborgene Kammer erleuchtet" $\left(E d f o u ~ \mathrm{II}^{2}, 16, \mathrm{I} 1\right)^{81}$ in einem Hymnus an Thot als Ibis einen tieferen Hintergrund erhalten. Für die Zulassung zum Spezialwissen ist offenbar eine Art von initiatorischem Verhör nötig, und dieses eben sehe ich im Thotbuch niedergeschrieben. Dabei würde ich die von den Herausgebern so sehr in den Vordergrund gestellten angeblichen Bezüge zur Unterwelt sehr in Frage stellen; im Wortlaut des Textes zumindest nach meinem philologischen Verständnis sind sie kaum zu fassen.

79 Vgl. insbesondere NH VI, 61,27-62,15. Auf die Tafel aus Türkis verweisen bereits die Editoren des Thotbuches (S. 70), der Verweis auf die Achtheit fehlt mutmaßlich deshalb, weil die Lesung dieser Stelle erst in den Nachträgen (S. 496) erkannt worden ist. Die potentiellen Implikationen, welche die Erwähnung des Türkis gerade im Hinblick auf das hermetische alchemistische Werk Tabula Smaragdina (Originaledition J. Ruska, Tabula Smaragdina. Ein Beitrag zur Geschichte der hermetischen Literatur (Heidelberg 1926); Verweis auf den Nag-Hammadi-Text bei T. Duquesne, Egypt's Image in the European Enlightenment, Seschat 3 (1999), S. 32-51, dort S. 37 f.) hat, können hier nicht verfolgt werden.

80 Vgl. hier etwa J. Assmann, Pythagoras und Lucius: Zwei Formen ägyptischer Mysterien, in: J. Assmann, M. Bommas (Hrsg.), Ägyptische Mysterien (München 2002), S. 59-75, dort S. $67 \mathrm{f}$.

81 Bearbeitet von S. Schott, Falke, Geier und Ibis als Krönungsboten, ZÄS 95 (1969), S. 54-65, dort S. $63 \mathrm{f}$. 
Die bemerkenswerte Passage am Anfang zeigt ganz gut, wie hier vom Schreiberlehrling zunächst einmal Entsagungen und hingebungsvolle niedere Arbeiten erwartet werden, und im Verein mit dem ganzen Tenor des Werkes berechtigt sie dazu, von einem initiatorischen Dialog zu sprechen. ${ }^{82}$ Für die Enthaltsamkeit in so vielen Bereichen dürften sich bemerkenswerte Parallelen in einer Tradition der jüdischen Hekhalot-Literatur finden, wo berichtet wird, wie Rabbi Yishma'el im Interesse von Erfolg beim Studium Enthaltsamkeit in Essen und Trinken auf sich nahm, sich vom Waschen und Ölen zurückhielt und auf Beischlaf verzichtete, weder scherzte noch jubelte und keinen Gesang oder Lied anstimmte. ${ }^{83}$

Diese Art von Spezialwissen hat auch Reflexe in anderen Texten hinterlassen. Auffällig ist es bereits, wenn auf der Statue Kairo JdÉ 37327 eine biographische Phrase erscheint „Einer, der eingedrungen ist in die Geheimnisse der Schriften des Re, der von der Wahrheit lebt. Ich bin einer in der Mannschaft des Ibis, der Gelehrten, der die ,Seelen des $\operatorname{Re}^{\mathrm{c}}$ erneuert". ${ }^{84}$ Der Bezug auf die „Mannschaft des Ibis" geht dabei evident auf die auch im Thotbuch themati-

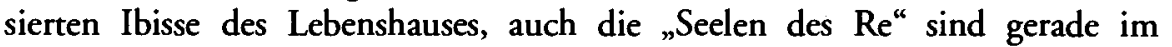
Thotbuch ein beliebter Begriff für religiös wichtige Schriften. Noch bemerkenswerter ist die Inschrift auf der Statue Kairo JdÉ 37128, wo es heißt „der instruiert ist in den ,Seelen des $\operatorname{Re}^{\prime}$ in der Kammer der Finsternis im Haus des Lebens. ${ }^{\text {"85 }}$ Die „Kammer der Finsternis“ ist hier rein logographisch geschrieben, so daß ${ }^{c} . t k k . w$ nicht strikt als Lesung abgesichert werden kann, ${ }^{86}$ doch dürfte die Deutung sachlich plausibel sein. Da die betreffende Statue etwa in die 30.

82 Auch die Bearbeiter diskutieren den Komplex der Initiation (S. 54-61), ihre Darlegung übersieht jedoch wichtige neuere Publikationen (z. B. J. Assmann, M. Bommas (Hrsg.), Ägyptische Mysterien? (München 2002)), und leidet u.a. darunter, daß sie fast wie ein automatischer Reflex von „rebirth“ sprechen, obgleich im Text selbst kein entsprechendes Vokabular auszumachen ist. Im übrigen demonstrieren A. Schlegel, H. Barry, Adolescent Initiation: A Cross-Cultural Code, in: H. Barry III, A. Schlegel (Eds.), Cross-Cultural Samples and Codes (Pittsburgh 1980), S. 277-288 (bes. S. 282), daß im Kulturvergleich die Initiation keineswegs standardmäßig mit Vorstellungen von Wiedergeburt verbunden ist.

83 P. Schäfer u. a., Übersetzung der Hekhalot-Literatur II. $\$ 81-334$, Texte und Studien zum antiken Judentum 17 (Tübingen 1987), S. 262 f. u. 302 f.; ders., Übersetzung der Hekhalot-Literatur IV. $\$ 598-985$, Texte und Studien zum antiken Judentum 29 (Tübingen 1991), S. 80 f.; R. M. Lesses, Ritual Practices to Gain Power. Angels, Incantations, and Revelation in Early Jewish Mysticism, Harvard Theological Studies 44 (Harrisburg 1998), S. 201 f. u. 412.

84 K. Jansen-Winkeln, Biographische und religiöse Inschriften der Spätzeit aus dem Ägyptischen Museum Kairo, ÄAT 45 (Wiesbaden 2001), S. 37 u. 347 Text f), Kol. 6-9.

85 Jansen-Winkeln, Biographische und religiöse Inschriften, S. 115 u. 381 Text a), Z. 1-2.

86 Jansen-Winkeln, Biographische und religiöse Inschriften, S. 117 Anm. 4 liest ${ }^{c} . t$ grh "Kammer der Nacht". 
Dynastie bis frühe Ptolemäerzeit datiert, ${ }^{87}$ kann sie auch einen nicht unbedeutenden Beitrag als terminus ante quem für das Thotbuch leisten. In phonetischer Ausschreibung begegnet der Begriff ${ }^{c} . t-k k . w$ als $\triangle$ _t in Wien (Nr. XX), der aus der Ptolemäerzeit stammt. ${ }^{88}$ Eine Parallelversion in Kairo hat statt dessen ${ }^{c} . t$ imn.t "verborgener Raum “ ${ }^{89}$ Daneben kennt man diesen Terminus noch aus einer bemerkenswerten Szene des Opfers der Schreibpalette in Edfu (Edfou IV, 247, 2)..$^{90}$ Die Verbindung wird noch relevanter, da der König in derselben Szene das Epitheton „der die Mannschaft des Ibis anleitet" erhält (Edfou IV 246, 17). Man wird diesen Begriff wohl generell in Beziehung zum Thotbuch zu setzen haben, so daß ein Blick auf weitere Bezeugungen lohnt.

Eindeutig in ein Gelehrtenmilieu führt auch ein Passus in der Stele der Chereduanch (Hildesheim PM 6352), Z. $3 \mathrm{f}$ im Rahmen einer Anrufung an die Vorbeigehenden. Sie lautet "Kollegium des Per-anch, welche die Schriften lesen, Mannschaft des Ibis, welche die Schriftrollen öffnen(?), ${ }^{91}$ Künstlerschaft des Thot, welche der Gottesrituale kundig sind. ${ }^{\text {"92 }}$ Ganz ähnlich heißt es auch in einer Anrufung auf der Stele Berlin 22489, Z. 10 „Künstlerschaft des Thot, Mannschaft des Ibis insgesamt". ${ }^{93}$

Generell dürften Tempelszenen mit Gabe der Schreibpalette als mögliche Reflexe des Thotbuches besonders verdächtig sein. Ein eklatanter Fall ist die Szene Edfou IV 389, 9-391, 2. Der König wird als „Sohn des Wen-Im“ bezeichnet $(389,16)$, somit in der Rolle stilisiert, welche auch der Kandidat im Thotbuch hat. Im Text zu den Göttern werden sowohl der Terminus "Seelen der Götter" für die Schriften verwendet $(390,7)$ als auch eine Ableitung „seit der Zeit des Tatenen“ $(390,14 \mathrm{f})$, die in Bezug zum „ersten Regierungsjahr des Tatenen" im Thotbuch stehen dürfte.

Sofern die Ableitung des Schlüsselworts $s l 3$ u. ä. im Thotbuch von altem sir akzeptiert wird, kann man auch eine gewisse Korrelation dieses Begriffes mit

87 Jansen-Winkeln, Biographische und religiöse Inschriften, S. $108 \mathrm{f}$.

88 W. Wreszinski, Aegyptische Inschriften aus dem K.K. Hofmuseum in Wien (Leipzig 1906), S. 160; Text C, Z. 24; Lesung des letzten Zeichens nach Wörterbuch-Zettel DZA 22.054.890.

89 Wresinski, Aegyptische Inschriften, S. 171.

90 Hinweis darauf bereits bei Jasnow, Zauzich, Book of Thot, S. 36 f. Kurze Erwähnung bei D. Budde, Die Göttin Seschat, Kanobos 2 (Leipzig 2000), S. 291.

91 Ich würde das Zeichen eher pg' als shn lesen wollen.

92 K. Jansen-Winkeln, Die Hildesheimer Stele der Chereduanch, MDAIK 53 (1997), S. $91-100$, dort S. 92 u. 96 Anm. h.

93 A. Scharff, ein Denkstein der römischen Kaiserzeit aus Achmim, ZÄS 62 (1927), S. 86107, dort S. $104 \mathrm{f}$. 
dem Stichwort der „Seelen des Re“ etablieren, vgl. etwa Edfou IV 89, 17-91, 2; Edfou IV 57, 1.

Einige Male wird im Text eine Lichtmetaphorik gebraucht. Hier geht es um Erleuchtung im wörtlichen (und übertragenen) Sinne, bei deren Formulierung man Dinge wie "Lampe auf dem Weg der Unwissenden; er erhellt die Finsternis“ in den Paralleltexten zu pAnastasi I, 3 oder auch „Fackel in der Finsternis vor der Armee, und er erleuchtet ihnen" pAnastasi I 17, 3 mit anderen Augen liest.

Bemerkenswert ist sicher die Erwähnung der „Halle der beiden Wahrheiten“ (B04, 7/8). Auf den ersten Blick mag dieser sonst aus dem Totengericht Tb 125 bekannte Bau darauf hindeuten, daß der vorliegende Text eine jenseitige Komponente hat. Tatsächlich dürften die Dinge aber anders liegen. Für TB 125 ist schon verschiedentlich erwogen worden, daß dieser Spruch nicht primär funerär ist, sondern einen Sitz im Leben anderer Art hatte. ${ }^{94}$ Meist wurde dabei an priesterliche Reinheitsvorschriften gedacht, ich habe mich aber aufgrund bestimmter Formulierungen der Nachschrift dafür ausgesprochen, vielmehr Amtseide im Zusammenhang der Zivilverwaltung anzusetzen. ${ }^{95}$ Gerade dieser Ansatz paßt sehr gut zum Thotbuch. Dort geht es um den Zugang des Schreibers zum exklusiven Wissen bzw. den sozialen Aufstieg des gut ausgebildeten Schreibers. „Er wird ein Vertrauter des Königs und seines Hofstaats werden" heißt es dazu in der Nachschrift von TB 125, 7-8.

Relevant ist im Rahmen einer überhöhten Konzeption des Ackerbaus der Vers „Man fürchtet sich nicht vor der Vergeltung eines Jahrs des Elends, man stirbt nicht an einem Jahr der [Not(?)]." (V01, 2/22 u. Par). Er steht in einem größeren Zusammenhang. Zu vergleichen ist speziell eine Passage in der Lehre des Djedfhor „[Lehre] deinen Sohn ${ }^{96}$ zu schreiben, das Feld zu bestellen, Vögel und Fische zu fangen, damit nicht ein Jahr der Armut entsteht, und er von dem [profitiert], was er mit seinen Armen leistet. ${ }^{\text {977 }}$ Vollständiger erhalten ist dieser Passus in der demotischen Lehre des Chascheschonqi als „Erzieh deinen Sohn zum Schreiben, zum Pflügen, zum Fischen und zum Vogelfang für ein Jahr, in dem die Überschwemmung ausbleibt, damit er den Profit seiner Tätigkeit

94 Vgl. etwa R. Merkelbach, Ein ägyptischer Priestereid, ZPE 2 (1968), S. 7-30; R. Grieshammer, Zum „Sitz im Leben" des negativen Sündenbekenntnisses, in: W. Voigt (Hrsg.), XVIII. Deutscher Orientalistentag vom 1. bis 5. Oktober 1972 in Lübeck. Vorträge, ZDMG Supplement 2 (Wiesbaden 1974), S. 19-25; J. Assmann, Ma'at. Gerechtigkeit und Unsterblichkeit im Alten Ägypten (München 1990), S. 140-149; J. Gee, The Requirements of Ritual Purity (Dissertation Yale 1998).

95 J.F. Quack, Organiser le culte idéal. Le Manuel du temple égyptien, BSFÉ 160 (2004), 9-25, dort S. $18 \mathrm{f}$.

96 HO 4, 3, Z. 3 sind am Anfang Reste von ' $s$ ' $=k$ ' erkennbar.

97 W. Helck, Die Lehre des Djedefhor und die Lehre eines Vaters an seinen Sohn, KÄT (Wiesbaden 1984), S. 9-11 mit allerdings überholtem Textverständnis. 
findet!“ $(17, x+23) .{ }^{98}$ Es dürfte nicht ohne Interesse sein, daß die Tätigkeit des Schreibens und Wissenserwerbs im Thotbuch gerade mit Bildern aus dem scheinbar so anders gelagerten Bereich der Landwirtschaft und des Fisch- und Vogelfangs ausgemalt wird.

In die Diskussion einbringen möchte ich auch Sargtext Spruch 1047/1048 aus dem Zweiwegebuch. ${ }^{99}$ Die Passage lautet in der textkritisch ursprünglicheren Fassung, die als Spruch 1048 ediert ist, „Ich bin ein Priester, der täglich für Osiris kocht. Mein Acker ist im Feld der Opfergaben unter den Gelehrten, unter denen, die das Chenemet-Brot für Osiris herstellen. Ich bin ein Schreiber zur Seite des Thot, ich bin der Aufwärter des Osiris unter denen, die Opfergaben herstellen. (Meine) zwei Äcker sind im Opfergefilde, es soll mir nicht genommen werden. ${ }^{100}$ Hier finden wir den intellektuellen Ackerbesteller und Gehilfen des Thot.

Noch ein weiterer Text sei ungeachtet der zahlreichen ungelösten Probleme, die ich noch mit seinem Verständnis habe, in die Diskussion geworfen, nämlich der Tadel an den Schüler, der im pAnastasi IV, 2, 4-3, 2 mit Parallele in pKoller 2, 2-3, 3 und pAnastasi $V, 5,1$ überliefert ist. ${ }^{101}$ Hervorzuheben ist dabei der nur hier belegte „Tag des Esels“, mit dem man bislang wenig anfangen konnte. Gerade angesichts der im Thotbuch so auffälligen Bewertung des Esels als eines Tieres, das zuerst Verstand gewonnen hat, wären dazu ganz neue Lesarten denkbar. Immerhin sind im Text an sich das Stichwort eines "Gehilfen “ (hrider Schiffer und der Vogelfang durchaus mit Motiven des Thotbuches vergleichbar.

Hier wartet also noch erhebliches Material darauf; unter dem Blickwinkel dieses faszinierenden Textes neu gelesen und in größere Zusammenhänge gebracht zu werden - die Zukunft wird sicher noch weitere Erkenntnisse bringen.

98 Für die Verbindung dieser beiden Textstellen s. P. Seibert bei Brunner, Zitate aus Lebenslehren, in: E. Hornung, O. Keel (Hrsg.), Studien zu altägyptischen Weisheitslehren, OBO 28 (Freiburg/Göttingen 1979), S. 119.

99 Über mögliche Verbindungen zwischen den Zweiwegebuch und dem Thotbuch sprechen bereits Jasnow, Zauzich, Book of Thot, S. 11, ohne dies jedoch im Detail auszuarbeiten.

$100 \mathrm{Vgl}$. B. Backes, Das altägyptische „Zweiwegebuch“. Studien zu den Sargtext-Sprüchen 1029-1130, ÄA 69 (Wiesbaden 2005), S. 69, 132 f. u. 278. Ich folge ganz der Version von Spruch 1048, die mir der Erstellung eines Mischtextes vorzuziehen scheint.

101 Textedition A.H. Gardiner, Late Egyptian Miscellanies (Brüssel 1937), S. 36 f; 57 u. $117 \mathrm{f}$; ; letzte Gesamtbearbeitung N. Tacke, Verspunkte als Gliederungsmittel in ramessidischen Schülerhandschriften, SAGA 22 (Heidelberg 2001), S. 54-57. 